\title{
C-A/AP/\#415
}

Dec 2010

\section{Burning and Propagation of Flame in Cable Trays at the AGS}

\author{
M. Plotkin
}

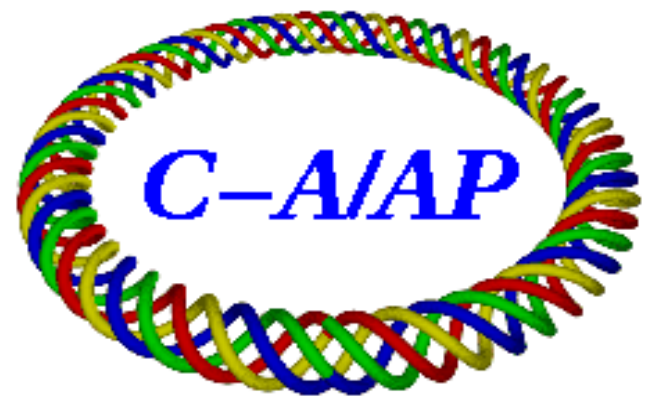

\section{Collider-Accelerator Department Brookhaven National Laboratory Upton, NY 11973}

Notice: This document has been authorized by employees of Brookhaven Science Associates, LLC under Contract No. DE-AC02-98CH10886 with the U.S. Department of Energy. The United States Government retains a non-exclusive, paid-up, irrevocable, world-wide license to publish or reproduce the published form of this document, or allow others to do so, for United States Government purposes. 


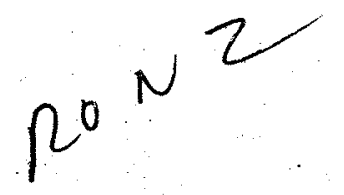

\section{BROOKHAVEN NATIONAL LABORATORY Associated Universities, Inc. Upton, New York}

ACCELERATOR DEPARTMENT

Informal Report

BNL 16759

AGS DIV 72-1

Burning and Propagation of Flame

in Cable Trays at the AGS

\section{Plotkin}

April 18, 1972

NOT I C E

This report was prepared as an account of work sponsored by the United States Government. Neither the United States nor the United States Atomic Energy Commission, nor any of their employees, nor any of their contractors, subcontractors, or their employees, makes any warranty, express or implied, or assumes any legal 1iability or responsibility for the accuracy, completeness or usefulness of any information, apparatus, product or process disclosed, or represents that its use would not infringe privately owned rights. 
I. Introduction

II. Description of Facility

III. Description of Cable Installations

A. Target Building

B. East Building

C. East Experimental Building Addition (EEBA)

IV. Description of Cables

v. The Fire Problem

VI. Types of Flame Tests

A. IPCEA Vertical Flame Test 6.19 .6

B. Bureau of Mines Test - Horizontal

C. Oi1 Bucket Test - Horizontal

D. Fisher Burner Test - Vertical

E. Ring Burner Test - Vertical

F. Oil Soaked Burlap - Vertical

G. Okonite Vertical Test

VII. Investigations

A. Oak Ridge

B. General Electric

C. Okonite Company

D. Cerro Wire \& Cable Company

E. Anaconda Copper

F. Bureau of Mines

G. Belden Wire \& Cable Company

H. duPont Company

I. IEEE Meeting

J. "F Lamemastic"

vIII. Tests Performed at BNL

IX. General Observations and Conclusions

X. Ignition Sources and Potential for Fire

XI. Proposed Protection Schemes

XII. Bibliography 


\section{Abstract}

The experimental facilities at the AGS utilize many miles of cable trays arranged in multiple vertical tiers around each building. The trays are filled with various types of control, signal, and power cables. This investigation was carried out to determine the potential for cable burning and flame propagation in these trays. Various cable manufacturers were contacted and visited and a number of tests were performed at BNL. The BNL tests simulated, in many cases, the exact configurations which exist in our installation. On the whole, the cables and configurations used at the AGS do not present a fire hazard.

\section{Introduction}

In order to determine the possibilities of a major fire being spread throughout the AGS experimental facility by burning cables in trays, an investigation has been made into this subject. The manufacturers of all the types of power cables used were contacted or visited. Tests were performed on each variety of power cable installed. Various cable manufacturers' reports and catalog information were studied.

This report will describe our findings, results and conclusions.

\section{Description of Facility}

The Target Building, East Building and East Experimental Building Addition (EEBA) of the AGS experimental area encompass a space approximately 135,000 square feet in area and about $50 \mathrm{ft}$ high (Fig. 1). The floor is extensively loaded with equipment relating to the experimental. program with the major portion of the contents of the Target Building consisting of concrete shielding. To support the beam transport equipment, large numbers of power supplies with high current capability are used to energize the various types of dipole and quadrupole magnets used in the beam lines. 
The $460 \mathrm{~V}, 3$ phase, ac power for these power supplies is distributed through a series of open top, ladder bottom, trays mounted in multiple tiers on the building walls about $30 \mathrm{ft}$ off the floor. The dc feeds to the magnets run, from the power supplies, throughout these buildings, partially in wall-mounted trays, but primarily running on the floor or in trenches, with or without trays.

The most common size of power supply has a $450 \mathrm{~kW}$ rating and each leg of the dc requires up to seven 535.3 MCM cables, a possible total of fourteen cables per magnet. In many cases, the power supply may be hundreds of feet from the magnets, requiring long runs of cable. The ac is fed to the power supplies from key-inter locked disconnect switches which are called "Royal Boxes." The major wall-mounted tray installations utilize 1000 MCM cable to supply the "Royal Boxes." The ac distribution to the power supplies is made with $535.3 \mathrm{MCM}$ cable, usually with six 535.3 MCM cables per power supply.

\section{Description of Cable Installations}

The buildings are orlented in a north-south direction and the descriptions will refer to the building walls by their orientation, e.g., "the west wall of the Target Building."

A. The Target Building was the first structure completed for experimental use. It straddles the main magnet ring and represents the only portion of the AGS ring where heavy concrete shielding is used instead of earth shielding. The four walls of the building have about 8 - 10 horizontal trays, stacked vertically about $30 \mathrm{ft}$ off the floor. Some trays are loaded with 1000 MCM neoprene-jacketed cable, some incidental small diameter neoprene-jacketed cables and $535.3 \mathrm{MCM}$ neoprene-jacketed cables. The cable insulation under the neoprene, on the large diameter, is code rubber (natural or synthetic rubber meeting IPCEA-NEMA specifications). The 1000 MCM power cables are arranged either in a triplex configuration, three cables laid in a triangle shape, Fig. 2, or are laid side by side. The 535.3 MCM cables are laid side 
by side, and the control cables are generally arranged in a parallel configuration.

Other trays are loaded with various coaxial and control

cables.

Cables which feed the transport magnets are 535.3 MCM cable, neoprene-jacketed, with cable insulation of code rubber, but some more newly installed cables have EPR insulation (ethylene-propylene rubber) under the neoprene. These $535.3 \mathrm{MCM}$ cables are mostly installed in floor trays or floor trenches.

B. The East Building has, on the average, five trays high on the east and north walls and about three high on the south and west walls, about $30 \mathrm{ft}$ off the floor. Here, again, control and power cables are separated in different trays. The $1000 \mathrm{MCM}$ cables are all in the wall trays. Some $535.3 \mathrm{MCM}$ cables are in wall trays, but most of it is installed on the floor or in trenches. This $535.3 \mathrm{MCM}$ is a mixture of neoprene over code rubber and neoprene over EPR. On the north wall on the east side, there is a tray installation carrying large numbers of coaxial cables in the computer complex outside the north wa11. This tray goes around a roll-up door.

On the east wall, on the outside, are a series of trays with 1000 MCM cables with cross-linked polyethylene insulation. Periodically, these cables enter the building, above the inside tray instailation and then drop down to the input of the "Royal Boxes."

\section{The East Experimental Building Addition (EEBA) was added to} the experimental area as part of the Conversion Program. This building is approximately $150 \mathrm{ft}$ by $350 \mathrm{ft}$ with a roof height of about $60 \mathrm{ft}$ to the peak. Its utilization and contents are similar to the Target and East Buildings.

With respect to cables and cable trays, the only difference in EEBA is the use of $1000 \mathrm{MCM}$ cross-linked polyethylene cable for the primary distribution of $460 \mathrm{~V}, 3$-phase, ac to the "Royal Boxes." This cable is installed in wall trays about $30 \mathrm{ft}$ off the floor, with the 
horizontal tray runs containing six cables arranged in two triplex configurations. The triplex groups consist of three cables in a triangular geometry. The two groups of çables in each 12-in. tray are separated by about $6 \mathrm{in}$. center to center. There are up to nine tiers of trays.

The feeds to the "Royal Boxes" drop down in vertical trays and, on these vertical runs, the cables are laid flat in the tray. The cable is Okonite $\mathrm{X}$-olene and the only filler in the cross-linked polyethylene is carbon black.

A11 other cables in the building are neoprene-jacketed 535.3 MCM cables or control and signal cables in separate trays.

IV. Description of Cables

The bulk of the cable installed in the experimental area is 535.3 MCM neoprene-jacketed cable. This cable is used to connect the ac, 3-phase, $460 \mathrm{~V}$ power source to the power supplies and to connect the dc from the power supplies to the magnets. Since the physical setup of the experimental beams is changed as the experiments are changed, there is no permanent layout and frequent rewiring of the system takes place. For this reason a very flexible stranding is used in the 535.3 MCM cables. It contains 1325 strands (nominally) of 非4 copper wire. The flexibility makes handling and rewiring simpler. These cables can be bent readily on a 12-in. diameter. These installations are all considered temporary.

Early installations used neoprene over code rubber and later installations use neoprene over EPR. Neoprene was chosen initially for its very good abrasion resistance. Many of our cables are laid on the floor and are subject to pedestrian and vehicular traffic. There are no jacketing materials, other than neoprene, on any of the 535.3 MCM cables.

The 1000 MCM cables are tray mounted only, on the building walls. These conduct the $460 \mathrm{~V}, 3$-phase, ac power to the distribution boxes. These setups are considered permanent. The requirement on flexibility is not present here and the stranding consists of 61 strands. This cable is quite stiff, but is acceptable for a one-time installation. Except 
as noted earlier, the 1000 MCM cable in the Target and East Buildings is a11 neoprene jacketed. In EEBA, the 1000 MCM cable is insulated with cross-linked polyethylene.

Multiconductor cables for light power and control purposes are now procured as per AGS Specification \#587. The insulation on conductors is polyvinyl chloride with a nylon jacket, a mylar tape wrap and polyviny 1 chloride outer jacket. The specification requires that the cable pass a vertical flame test as given by the IPCEA (Insulated Power Cable Engineers Ass'n.)

V. The Fire Problem

The first ideas on fire protection of the experimental area involved an overall sprinkler system. Further examination indicated that, not only would this be very expensive, but it would not be efficient in extinguishing fires. The sprinkler heads would have to be located above the crane and would then be far enough from the floor that a fire would have to be extremely large to set off the heads. Because of this, it was decided to protect sources of combustible materials on the floor and to protect the cable trays as a separate item. The major sources of fuel in the buildings at this time are trailers, wooden decking and stairs and experimental setups. The trailers are being protected by Halon 1301 systems inside, and external sprinklers on top. The hazardous experimental setups will have local sprinkler protection and the wooden decks and stairs have largely been replaced by metal assemblies.

At first it was thought that the cable trays could be protected by sprinklers mounted on the walls, but further investigation indicated that, in multiple tier trays, there is a problem if the fire is in the lower trays. There is no simple way to mount the heads to cover all potential fires.

The next step in the investigation was to examine the types of cables used and their actual fire potential. If it could be demonstrated that a cable array was nonpropagating and self-extinguishing, under the 
conditions present in our installation then the need for separate protection of the cable trays vanishes.

\section{Types of Flame Tests}

There are many different flame tests used by various manufacturers, users and government agencies to determine the resistance of a cable or cable array to flame propagation. Efforts are under way by the IEEE and the Underwriters Laboratory to try to develop a standard test. Unfortunately, there are so many parameters involved that it is difficult to establish a "standard" test which will serve to answer al1 possible questions.

The parameters which come into play include:

1. type of insulation, jacket, tape, armor, fillers, etc.

2. size of conductor

3. density of packing in the tray

4. arrangement and orderliness of packing in the tray

5. size and type of tray

6. orientation of the tray, vertical or horizontal

7. environment, air flow, draft, chimney effects, etc.

8. type, temperature and duration of ignition source.

Some of the tests used try to duplicate an exact set of environmental conditions. Others attempt to reproduce a standard set of conditions from which general conclusions may be established. A brief description of some of these tests are given below.

A. IPCEA Vertical Flame Test 6.19.6 (Insulated Power Cable Engineers Ass'n.)

In this test the specimen is held vertically in a prescribed test chamber. A Tirrell burner with a pilot light is mounted on a $20^{\circ}$ angle block. The fuel is illuminating gas at normal pressure. A paper flag is attached to the specimen $10 \mathrm{in}$. above the spot where the inner blue core of the flame is applied. The burner is cycled on 15 seconds 
and off 15 seconds for 5 cycles. If more than $25 \%$ of the extended portion of the paper flag is burned, the specimen has failed the test.

\section{B. Bureau of Mines Test - Horizontal}

The specimen is heated to $400^{\circ} \mathrm{F}$ conductor temperature by passing a current equal to 5 times its rating through it. At this time, a Tirrell burner with natural gas fuel, ad justed for a 5-in. flame height, 3-in. inner core is placed under the cable. After one minute, the current and ignition source are turned off. A cable fails this test if the burned area exceeds $6 \mathrm{in}$. or if afterburn exceeds 4 minutes.

\section{c. Oil Bucket Test - Horizonta1}

A five gallon bucket of transformer oil is placed with the oil surface 6 in. below the tray. The tray is loaded with one layer of cable spaced a half-diameter. The oil is ignited with a torch and the time is recorded to electrical failure. The fire in the bucket is then extinguished and the time for the cable fire to extinguish and the propagation distances are noted. In this, and the following tests, failure is determined from the customer's requirements.

\section{Fisher Burner Test - Vertical}

This test is similar to " $\mathrm{A}$ " except the burner is a Fisher burner and the flame is left on continuously for 20 minutes. No flag is used but the time to cable failure, duration of afterburn and length of burn are recorded.

\section{E. Ring Burner Test - Vertical}

The sample is free hung, vertically, and a ring burner with a $4 \frac{1}{4}$ " i.d. and 22 flame apertures is adjusted for a 4.51 iter/minute gas flow and all blue flame. The time to electrical failure is noted, and the burner flame is extinguished. Time of afterburn and propagation are recorded.

\section{F. Oil-Soaked Burlap - Vertical}

A 24" X 24" piece of burlap is soaked in transformer oil and wrung out for a retention of about $2 \frac{1}{2}$ oz of oil. This is fastened to the 
cables arranged in one layer in a tray with a half-cable diameter spacing. The burlap is ignited and allowed to burn out. Propagation is recorded.

\section{G. Okonite Vertical Test}

A line burner with an output of $70,000 \mathrm{Btu} /$ hour is positioned horizontally, facing the tray, with four cables spaced a half-cable diameter. The fuel is illuminating gas. The flame is adjusted for a $14-16 \mathrm{in}$. length and a flame temperature $1400^{\circ} \mathrm{F}-1500^{\circ} \mathrm{F}$ at point of impingement on the cable. Duration of flame is 20 minutes. Afterburn and propagation are recorded.

It is obvious that these tests, which differ markedly, coupled with the other parameters as mentioned earlier, will make it difficult to establish a single, accepted, industry-wide test.

\section{Investigations}

\section{A. Oak Ridge}

The first method of cable tray fire protection which was checked during a visit to Oak Ridge by M. Plotkin, R. Young and J. Dietz involved a method developed at Oak Ridge and now in use on cable trays in the power building for the $\mathrm{k}-25$ plant. It had been estimated that sprinkler protection of cable trays, at that installation would cost in the hundreds of thousands of dollars due to the quantity and complexity of the installation. It was found that vermiculite, in polyvinyl chloride bags, laid continuously on the cables, would act as a fire suppressant. Vermiculite is an inert hydrous mica which, upon heating, exfoliates and expands to many times its original volume. This expanded material is nonflammable and is supplied in different grades and sizes. Oak Ridge used the \#3 grade (fine) and in tests found that a bag of vermiculite laid on a cable tray in which an intense fire was established, would extinguish the fire in 5 seconds when the flames reached the bag. The bag melts and the fine, dry vermiculite spills out and smothers the flame. Documentation of these tests is available from Oak Ridge.

Another significant fact that was determined at Oak Ridge was that the orientation of cables in trays determined, to a significant 
degree, the capability to start a propagating fire. Pieces of truck signal flares, cut to burn about 5 minutes, were ignited at the end of a cable tray. If the cables were neatly arranged parallel to each other, and closely spaced, a propagating fire would not start. If the cables were jumbled, allowing air flow between the cables, a propagating fire would start. Some tests were done using sprinkler heads over the tray in a multitier arrangement and it was found that the fire could outrun the sprinkler actuation.

These tests were done on control cables with a plastic jacket in trays with closed bottoms. The installation has trays either 3 or $4 \mathrm{ft}$ in width and a vendor supplied bags of vermiculite, $3^{\prime} \times 4^{\prime}$, with a $10 \mathrm{mil}$ PVC plastic. The cost of the total installation was about one dollar per square foot of tray.

In applying this method to the BNL installation, we had to look at several differences between the Oak Ridge setup and ours. At Oak Ridge, as at most nuclear plants and major industrial installations, circuit integrity is very important. That is, in the event of a fire, control cables should not lose their electrical function for some period of time, perhaps up to 20 minutes to a half hour, once the fire is started. This allows time to shut down an installation in a safe manner. This factor is not important in the BNL installation since there is no possibility of a radioactive spill and the systems are well protected against short circuits and other electrical failures. Another difference in the BNL facility is the use of ladder-bottom trays. Although most control trays are heavily filled with cable and the vermiculite will not filter through the cables, some trays are lightly filled and it may be necessary to install sheet metal bottoms on these trays. A third difference is that, at Oak Ridge, the cables are run below their rated ampacities (current carrying capability commensurate with temperature rise). The addition of vermiculite bags directly on the cable reduces the ampacity due to the restriction of air flow. If space permits, the bags may be spaced above the cables to allow proper air circulation. In the BNL installation, power cables are run at rated ampacity and could not stand the derating 
required. In addition, the trays are too closely spaced to allow the bags to be spaced above the cables. Control and signal cables are run well below rated ampacity and the vermiculite represents a good solution to the fire protection problem.

(As a result of this visit we will conduct tests on an assortment of all kinds of control, signal and minor power cables, in trays, simulating the configurations which exist in the AGS main ring and in the control cable trays in the experimental areas. At the present time, some preliminary tests show that 非 3 vermiculite in a 5 mil PVC bag will protect, adequately, all our horizontal control cable trays. Vertical configurations will require a different form of protection.)

\section{B. Genera1 Electric}

In the summer of 1971, General Electric Company conducted a seminar, at their New York office, on flame resistant cable insulations. Don Davis, AGS; John Dietz, Safety Office; Lewis Jacobson, PEP; and M. Plotkin attended this seminar. It was directed towards a new flameretardant cable insulation, "Flamenol XL." This is a cross-1inked polyvinyl chloride which is thermosetting. Various comparisons between "Flamenol XL" and other cable insulating materials were made.

One very significant test which was used was the Oxygen Index Test. In this test, a sample of insulating material is inserted in a glass chimey with a controlled atmosphere of oxygen-nitrogen. The percentage of oxygen is adjusted so that a flame is just maintained. Since $21 \%$ represents a normal atmospheric percentage of oxygen, a value of the Oxygen-Index (0.I.) of $25 \%$ or greater represents an essentially nonburning material. If the $0 . I$. is under $21 \%$, it will burn quite readily. It must be emphasized that these tests are on the insulating material only, without the presence of a conductor. Figure 3 shows the relative $0 . I$. values for various materials.

Some discussion was held on the methods of testing cables for flame propagation. The oil-soaked burlap vertical tray test was used. In this test, a "standard" piece of burlap is soaked in transformer oil, folded in a prescribed manner and is wired to the cables in the tray. It burns for 15 to 20 minutes. It serves to distinguish between propagating/ self-sustaining and nonpropagating/self-extinguishing cables. 
In January 1972, the GE plant in Bridgeport, Connecticut was visited and time was spent with $\mathrm{J}$. Robertson who has been conducting tests for $\mathrm{GE}$. In his more recent efforts, he has been attempting to reproduce the results obtained by the okonite Company, in the cable burning tests. These tests involve a gas burner as has been described. Robertson's tests showed that there are still too many variables. These include type of gas, gas flow, length of flame, temperature of flame, etc. With a large enough, hot enough flame, any organic material will burn and there will be difficulty in reproducing tests from one manufacturer to the next.

In general, all results show that neoprene-jacketed cables, with the very high 0. . . of neoprene $(>25 \%)$ are self-extinguishing/nonpropagating.

Some further observations on GE's work will be discussed in the section on the IEEE meeting.

\section{Okonite Company}

On December 2, 1971, Don Davis and M. Plotkin visited the Okonite Company plant in Passaic, New Jersey to witness flame tests on cables. These were being conducted for representatives of the Washington, D.C. subway system, now under construction. The principal investigator at Okonite is F. McAvoy.

The tests we witnessed in the morning, were made to show the difference between a PVC-polyethylene cable and neoprene-rubber cable. The first class of cable, tested vertically with a $70,000 \mathrm{Btu} / \mathrm{hour}$ burner at $1500 \mathrm{~F}$ temperature, burned well above the source of flame and continued to burn after the burner was turned off. The neoprene-jacketed cable burned only about a foot above the burner flame and then selfextinguished, even with the burner on. The Okonite engineers stated that it is the neoprene jacket which provides the protection. In neither test was there any damage to the cable more than an inch or two below where the burner flame impinged. 
The Okonite engineers further stated that in horizontal tests on neoprene-jacketed cable using a ring burner at $120,000 \mathrm{Btu} / \mathrm{hour}, 1500^{\circ} \mathrm{F}$, the only damage to the cable was a circular burn essentially the size of the burner. There was no lateral propagation at a11. A further observation they made was that the heavier the copper conductor, the less damage and spread that would take place making $500 \mathrm{MCM}$ and $1000 \mathrm{MCM}$ better from the standpoint of fire protection than small control cables. Another observation by the Okonite staff was that the worst thing to have is a closely covered tray. This acts like an oven and speeds the evolution of flammable gases and subsequent propagation of flame.

Frank McAvoy delivered a paper at the IEEE meeting in New York. on January 31, 1972. This will be discussed later.

\section{Cerro Wire and Cable Company}

On December 16, 1971, W.G. Walker, AGS, and I visited the Cerro Wire and Cable Company plant in New Haven, Connecticut. Although BNL does not have any Cerro cables in its installation, the Cerro staff were extremely helpful and informative.

The Technical Director of Cerro, George Buettner, is very knowledgeable in the area of cable burning and is involved with the IEEE and other groups who are attempting to standardize cable tray fire tests. Several hours of discussion were held and again, it was stated that, with one exception, neoprene-jacketed cables would not propagate a flame. The one exception is a very special one: for certain military applications where flexibility is required from arctic temperatures to desert temperatures, large amounts of plasticizer are added to the neoprene. This may increase the flammability but no commercial cables are fabricated in this fashion. The material under the neoprene (buty1, EPR, etc.) may be flammable, but is protected by the neoprene which carbonizes, swells and subsequently protects the inner insulation. It was also stated that heavier inner conductors, 500 MCM vs control cable, improve the situation by carrying away the heat.

In their $1 \mathrm{ab}$, we witnessed tests on several different control cables. The tests were run vertically (worst case) under a hood, natural 
draft, using a Fisher type burner. The PVC jacketed cables burned readily and propagated, the neoprene-jacketed cables just burned in the flame with no propagation.

In the Cerro catalog for flame retardant and radiation resistant cables, there are five different cables listed. Three of these are neoprene jacketed and pass the "bucket fire propagation test" (horizontal tray with burning oil bucket), the Fisher burner test (vertical tray), the vertical ring burner test (a ring burner surrounds a free hung vertical wire) and the oil-soaked burlap test (vertical).

\section{E. Anaconda}

On December 21, 1971, Frank Heimburger, AGS, and I visited the Anaconda Company cable plant in Marion, Indiana. Anaconda has received an order from us for 50,000 ft of 535.3 MCM cable (neoprene jacket over EPR rubber) for use in the experimental area. Two of their engineers, Ted Hansen and Floyd Wilson, are doing many varieties of flame tests on cables with particular attention to Bureau of Mines tests which are more stringent than the IPCEA tests.

They demonstrated many of these tests for us. The Bureau of Mines test consists of running the cable horizontally and passing enough current through it to obtain a conductor temperature of $400^{\circ} \mathrm{F}$. A Fisher burner is ignited under the cable and the specifications then require certain maximum propagation distances and burning times after flame is removed. This is a severe test because the organic insulations are already heated to $400^{\circ} \mathrm{F}$. This test is included in schedule $2 \mathrm{G}$ approved March 19, 1968, entitled "Electric Motor-Driven Mine Equipment and Accessories." It is issued by the U.S. Department of Interior, Bureau of Mines. Section 18.64 outlines the applicable specifications.

Other tests demonstrated included a vertical test with a paper flag taped on a prescribed distance above the flame of a Bunsen burner. The flame is then turned on 15 seconds, off 15 seconds for a given number of cycles. The paper is not supposed to burn. With neoprene or Hypalon, the paper generally doesn't burn even if the flame is continuous. 
Hypalon (a duPont trade name for chlorosulfonated polyethylene) is being used by Anaconda as a jacketing material and also as a single combined jacket insulation material. In addition to quoting neoprene jacketed, EPR insulated cable for our order, they quoted Hypalon over EPR and an all Hypalon covering, both at lower cost. They are quite sold on Hypalon and feel that it is slightly better than neoprene for flame retardant properties and equal in various mechanical properties such as abrasion and tear resistance. Its application at Brookhaven may be limited by the fact that the stiffness of Hypalon rises rapidly as the temperature is reduced. Since much of our cable is used outdoors, the loss of flexibility would present a problem.

\section{F. Bureau of Mines}

During my visit to Anaconda, I was given the names of the people at the Bureau of Mines in Pittsburg who conduct the tests on cables. Frank Lee is the engineer and his chief is Frank Gibson. On January 4, 1972, I called Lee and spoke to him about burning of cables. I wanted to get information on their tests and test results. Lee told me that some neoprene pass their test and others do not, but he also said this is a matter of degree since their test is very stringent with regard to time of burning after flame is removed and to distance of propagation along the cable.

After describing our requirements, he indicated that the neoprenejacketed cables would meet our needs and in talking about 500 MCM and 1000 MCM cables, stated that a flame on these made the equivalent of a "vaccination mark" and that's about a1l.

\section{G. Belden Wire \& Cable}

R. Spade was contacted by phone at Belden. He has done a lot of testing, but not on large diameter cables. He confirmed the capability of neoprene-jacketed cables to prevent flame propagation. He gave me information about a paper presented in Connecticut by $D$. McCormack of duPont. This paper described the properties of neoprene and Hypalon. 


\section{H. duPont}

Charles McCormack of duPont was contacted and he sent a copy of his paper entitled "Neoprene and Hypalon-Flame Resistance and Thermal Decomposition." The paper stresses the flame resistance of these compounds and the wide use which has been made of it in many applications. He indicates the high value of $0 . I$. readily attainable with neoprene $(>27 \%)$ and ascribes this high value to the fact that, in chlorinate polymers, the hydrogen chloride released during thermal decomposition modifies the chemical reactions occurring in the flame. Very often, calcium carbonate is added as a filler to neutralize some of the hydrogen chloride released, but Table II in his report still shows $0 . I$. values $>28 \%$

\section{IEEE Meeting January 31,1972}

The writer attended the IEEE meeting at the statler-Hilton Hote1, New York City. A paper was presented by F. McAvoy of Okonite Company, on cable flame tests. Although this facility in New Jersey was visited several months prior, some of the information presented was new.

Cables were tested in a closed bottom tray with a closed top. The tray was in the form of a " $U$ " with a flat bottom, a $2 \mathrm{ft}$ radius curve and vertical sides. Cables in one of the vertical sides was treated with "Flamemastic", a commercially available flame resistant coating for cables. The cables were control cables and power cables with EPR and neoprene on individual conductors and neoprene jacket on the control cables and neoprene over EPR on the power cables.

The fire was initiated by heating the bottom of the tray and the cable burned very well for $\approx 3 \frac{1}{2}$ hours. (The flame was kept on for $\approx 20$ minutes.) The "Flamemastic" was severely attacked but did stop the flame. With a closed bottom tray and a louvred cover, another test indicated similar damage but the actual fire was more severe and the burning damage occurred in about $1 \frac{1}{2}$ hours. Again, the "Flamemastic" stopped the spread of the fire.

The paper was followed by a discussion period with the major comment being a presentation by Robertson of $\mathrm{GE}$, complete with slides. 
This more or less was the same presented to me during my visit to Bridgeport on January 26. It dealt with the difficulty of establishing a "standard" test such as expressed by McAvoy. Such factors as gas composition, gas flow, flame temperatures, flame length, etc. make it extremely difficult to reproduce data from one lab to another.

\section{J. "Elamemastic"}

"Flamemastic $71 "$ is a fire protective coating for cables made by the Dyna-Therm Corporation. This material has been tested by the Factory Mutual Research Corporation. Tests were conducted on cables with aluminum conductor $2 / 0$ size. The insulation was cross-linked polyethylene and some $15 \mathrm{kV}$ rated cables were jacketed with polyviny 1 chloride. The conclusions from their report dated July 22, 1970, entitled "Flamemastic $71 \mathrm{~A}$ from the Dyna-Therm Corporation" are quoted as follows:

"1. The tests show that a 1/16 inch coating of Flamemastic $71 \mathrm{~A}$ on randomly grouped cables in a cable tray will not cause the cables to heat excessively when operated in accordance with the current limitations specified by the National Electrical Code for such conditions.

2. The fire test shows that a self-spreading fire will not occur in cables of the type employed in this test when installed in either horizontal or vertical cable trays and are coated with $1 / 16$ inch of Flamemastic $71 \mathrm{~A}$ and exposed by a fire of moderate intensity.

3. Flamemastic $71 \mathrm{~A}$ complies with Factory Mutual requirements and is approved for the protection of grouped combustible insulated cables against a self-spreading fire originating within the cables or from exposure to an external ignition source of moderate intensity."

This, or similar materials, can be used to protect portions of our cable systems where there is ready accessibility for application of the coating. 
VIII. Tests Performed at BNL

Because of the variety and complexity of the tests which are used in different places, it was decided to adopt a test procedure which would represent a severe case. For example, the IPCEA calls for a 15 second test five times with a Tirrell burner. Another test calls for a Fisher burner test for 20 minutes. By adopting a test using two Fisher burners for periods of time up to 30 or more minutes, a much more severe thermal environment can be created. No tests were performed using electrical current as a conductor heating source since our maximum conductor operating temperature is only $150^{\circ} \mathrm{F}$.

For the first tests, a Tirrell burner was mounted on a $30^{\circ}$ stand $\left(30^{\circ}\right.$ to the vertical) and the fuel was acetylene. The acetylene provides a very large value of $\mathrm{Btu} / \mathrm{ft}^{3}$. The setup was installed in a hood with transite sides and a glass door. Because of ventilation and smoke problems in the room, the exhaust fan in the hood was turned on for all tests. This provides a measure of forced draft which may make the test more severe.

For the first series of tests, color polaroid pictures were taken. Subsequent tests used conventional photography, making copies and slides easier to obtain. Since the results on all single neoprene-jacketed cables were similar, no photographs are included for these tests. Photographs of the tests on a multiple arrangement of neoprene and crosslinked polyethylene jacketed cables are shown.

A $3 \mathrm{ft}$ section of $12 \mathrm{in.} \mathrm{ladder} \mathrm{tray} \mathrm{was} \mathrm{used.} \mathrm{It} \mathrm{can} \mathrm{be} \mathrm{set} \mathrm{up}$ vertically or horizontally. The cable, or cables, to be tested are wired into position in the tray. Three foot samples of each type of $535.3 \mathrm{MCM}$ and $1000 \mathrm{MCM}$ cable used in the experimental areas were procured for these tests. The first set of tests was done on the following individual cables used in the experimental areas. These represent all installed types.

1. Rome Cable Company - Type RHW 600 V $75^{\circ} \mathrm{C}$ neoprene jacket, code rubber insulation, 1000 MCM. 
2. General Electric - neoprene over $535.3 \mathrm{MCM}$.

3. General Cable Company - neoprene over EPR, 535.3 MCM.

4. Rome Cable Company - neoprene over EPR, 535.3 MCM.

5. Okonite Cable - X-olene RHH- $90^{\circ} \mathrm{C}$ or RHW- $75^{\circ} \mathrm{C} 600 \mathrm{~V}$, cross-1inked polyethylene.

6. Multiconductor cable.

Test Results

A. Cable 1 - Rome - $1000 \mathrm{MCM}$

a. Burn time - 15 minutes

b. Afterburn - zero (some smoldering, no flame)

c. Length of burned area $-9 \frac{1}{2}$ in.

d. The back of the cable insulation at the point of contact of the flame was not burned.

B. Cable $2-\mathrm{GE}-535.3 \mathrm{MCM}$

a. Burn time - 15 minutes

b. Afterburn - zero (some smoldering, no flame)

c. Length of burned area - 11 in.

d. The back of the cable insulation at the point of contact on the flame was not burned.

C. Cable 3 - General Cable - 535.3 MCM
a. Burn time - 15 minutes.
b. Afterburn - zero (some smoldering, no flame)
c. Length of burned area -8 in.
d. No burning on back of cable.

D. Cable 4 - Rome - 535.3 MCM
a. Burn time - 15 minutes
b. Afterburn - 17 seconds (very little smoldering)

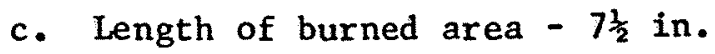
d. No burning on back of cable. 


\section{E. 1000 MCM Cross-Linked Polyethylene}

Ordinary cross-linked polyethylene insulated cables, in smali sizes, represent a potential fire hazard. Information obtained from various cable manufacturers indicated that the heat sinking of 1000 MCM conductors would make a substantial difference in the burning properties of cables. For this reason, an extended series of tests were conducted at BNL to determine the behavior of the BNL cables as installed, a triplex arrangement horizontally and a flat arrangement vertically.

\section{Single Conductor Vertical}

The first test was conducted on a three foot section of Okonite 1000 MCM cable mounted vertically in the center of a 12-in. tray. A Tirrell burner using acetylene was set up to apply a flame at a $30^{\circ}$ angle to the cable. The tests were done in a transite-sided hood with the exhaust fan on. After ten minutes of burning; there was some burning on the cable below the ignition flame due to the melting insulation running down the cable. The burning above the ignition source had almost stopped. At 14 minutes into the test, burning above the ignition source had stopped completely. Some burning below the ignition source was still evident. The ignition source was removed after 15 minutes. The afterburn above the flame point was zero. The afterburn below the flame point was a very small fire which persisted for 80 seconds. The burned length of cable, above the flame, was $14 \mathrm{in.}-15$ in. Below the flame point, the outer surface of the cable showed some scarring where the burning melt had run.

\section{Triplex Horizonta1 - First Test}

Three Okonite 1000 MCM cables were arranged in a triplex centered in the horizontal tray. A single Tirrell burner, using acetylene, was positioned to hit the triplex at a $30^{\circ}$ angle. The tip of the burner was 3 in. from the bottom of the cable. 
At two minutes into the test, burning drips began. By. eight minutes into the test, the dripping had stopped and no further burning was taking place in the region of the ignition source. Some surface burning was occurring on one side of the cable. The test was ended after 15 minutes. The afterburn time at the ignition source was zero. Surface burning of a very small flame continued for five minutes and affected a surface length of $4 \mathrm{in}$. on one side. The burned length (down to the copper) was about 6 in. at the point of application of the ignition source.

\section{Triplex Horizontal - Second Test}

With a similar setup to test $B$, two Tirrell burners were used with the tips about $2 \frac{1}{2}$ in. from the cables. The two burners were positioned to strike the same side of the triplex about 1 in. apart. At seven minutes into the test, the gas tank was emptied and the test was stopped. An afterburn time of about one minute of a very small flame was observed. Large amounts of soot were deposited on the cable. Twelve to fifteen minutes later, the test was restarted in the same spot. After 20 more minutes, the flame was removed. The afterburn time on one side was 3 minutes, 50 seconds, and on the other, 6 minutes, 50 seconds. The burners had deposited soot due to improper combustion and these tests were repeated.

4. Test on Array of Two 535.3 MCM Neoprene Cables and One 1000 MCM Cross-Linked Polyethylene Cable

Three cables were set up in a vertical tray. These were cables of the same type as cables, 3 and 4 in Section VII, with a cross-linked polyethylene $1000 \mathrm{MCM}$ cable in the center and the 535.3 cables on each side.' The cables were arranged with a half-diameter spacing starting at a point about 6 in. above the point of impingement of the flame. Below this point, they were touching. With this configuration, the cables 
could be uniformly heated by two burners but still provided the possibility of chimey effects where they separated. For this test two fisher burners, with propane as the fuel, were used. The burners were positioned to strike at the points where the cables touched. Figures $5=10$.

a. Burn time 20 minutes

b. Afterburn - 1000 MCM - 1 minute, 30 seconds Cable $3-0$ Cable $4-0$

c. Length of burn - 1000 MCM - 12 in.

Cable $3-8 \frac{1}{2}$ in.

Cable $4-7 \frac{1}{2}$ in.

5. Repeat of Test - Triplex Horizontal - Third Test A triplex was set up horizontally, centered in a 12-in. tray. Two Fisher burners with propane fuel were arranged to strike the triplex from both sides. The burn time was 20 minutes. The afterburn time was 3 seconds. The length of burned cable was 7 in. and $7 \frac{1}{2}$ in. on the bottom two cables and $5 \mathrm{in}$. on the top cable. Figures $11-18$.

6. Triplex Horizontal - Fourth Test - Effect of Burning Drippings

The setup of test 5 was used with the burners moved nearer one end to an undamaged section of cable. Three one foot lengths of 1000 MCM X-olene were placed side by side directly underneath the triplex where the burners were applied. The distance from the bottom of the triplex to the top of the three one foot pieces of cable was $6 \frac{1}{2} \mathrm{in}$. The test was started and the burning drippings were landing on the lower cables. At intervals of 5,10 , and 15 minutes into the test, the lower cables were examined. At each time, the drippings were still burning on the lower cables but the cable insulation itself was unaffected. At 20 minutes, the ignition source was removed. The dripping had already stopped and no flame or 
damage was noted on the lower cables other than a buildup of residue from the drippings. On the triplex, the afterburn time was 80 seconds on the side nearest the first burn test (Test E). There was zero afterburn time on the other side. The lengths of the burned areas on the triplex were 7 in. and $7 \frac{3}{2}$ in. on the lower cables and 3 in. -4 in. on the top cable.

\section{Three 1000 MCM Cross-Linked Polyethylene Cables}

\section{Side by Side}

Three $3 \mathrm{ft}$ lengths of Okonite 1000 MCM cross-1inked polyethylene cables were arranged vertica11y. Two of the cables, the left and center, were touching for the full length. The third cable, the right one, was spaced about one half a cable diameter except at the point of flame impingement where it was bent to touch the center cable. The two Fisher burners with propane fuel, were positioned to strike the cables where the outer cables touched the center cable.

During the test, burning material would periodically roll down the cable below the ignition point. These flames were about the intensity of a match flame. They would appear then go out, then reappear. At 15 minutes into the test, a11 yellow flame above the ignition source disappeared and no further burning took place during the test. The test was terminated at 35 minutes. There was no afterburn above the ignition source and a 3 minute afterburn near the bottom of the center cable with an intensity less than a match flame.

The area of severe damage totaled 9 in. $-10 \mathrm{in.}$ on a11 three cables. The left hand cable showed some puckering for another $3 \mathrm{in}$. The center cable shbwed some puckering for another $4 \mathrm{in.}-5 \mathrm{in}$. In the space between the right and center cables, some minor damage was shown for 4 in. - 5 in. above the severe damage region on both cables. Figures $19-28$. 


\section{F. Tests on Multiconductor Cables}

A four conductor cable procured on Spec. AGS-587 was tested vertically and horizontally. The conductor insulation is PVC with a nylon jacket. There is a mylar tape wrap and a PVC outer jacket.

This specification requires the following:

"Conductor Insulation: Flame retardant, moisture resistant polyvinyl chloride.

Sheath: Flame retardant, moisture resistant, abrasion resistant polyvinyl chloride, colored black.

Vertical flame tests on the completed primary conductor with the nylon jacket in place shall also be included following the procedures in IPCEA Standard S-61-402, Part 6.5."

A short length of cable was positioned horizontally with two Fisher burners hitting it, one from each side. After about fifteen minutes, there was no more burning of combustible material taking place. There was no afterburn and the burn length was 8 in.

Two, $3 \mathrm{ft}$ lengths of cable were arranged vertically, spaced about a half-diameter. Two Fisher burners hit the cables from the front. At 4-3/4 minutes into the test, the cable stopped burning above the flame. Only some small yellow flames were still present below the point of impingement of the ignition source. At seven minutes, this too, disappeared but reappeared at $8 \frac{1}{2}$ minutes. This is due to the continued heating of the copper. At ten minutes, the test was halted; the afterburn time was 22 seconds, all below the ignition point. The burn damage length was 17 in.

IX. General Observations and Conclusions

As a result of the preceding tests, discussions and investigations, a general set of observations and conclusions can be presented.

1. A cable or group of cables which does not propagate a flame in a vertical direction will not propagate a flame in a horizontal direction. (This is the experience of all manufacturers and BNL tests.) 
2. A tray that is heavily loaded with cables will not support a propagating fire as readily as one that is lightly loaded with spaces between cables. (GE, Cerro, Okonite and Anaconda use 3 or 4 cables spaced on half-diameter as the most severe test.)

3. A tray neatly loaded with touching, parallel cables will not propagate a fire as readily as one in which the cables are jumbled. (Oak Ridge experience.)

4. The size of the conductor has a strong affect on the flame properties of the cable. A large diameter conductor may heat sink enough to prevent a propagating fire with an insulation which will propagate in small diameter cables. (Based on BNL tests and discussions with cable manufacturers.)

5. In a fire which is hot enough and large enough, any organic material will burn. Some will propagate beyond the ignition source, others will not depending on many factors.

6. The details of the ignition source play a very important role in the results of any type of test. (GE and Okonite tests.) (Ref. 8, 10, 18).

7. Neoprene, Hypalon, cross-linked polyvinyl chloride, inorganically insulated, silicone insulated and certain filled plastic materials will not, in genera1, propagate a fire. (Ref. 1, 3, 8).

8. Under certain conditions, with large copper conductor heat sinkings, cross-linked polyethylene insulated cables will not propagate a fire. (BNL tests.)

9. Cable coating compounds are available which will convert a propagating material into a nonpropagating one. (Ref. 6)

10. Trays should not be covered, top and bottom, if any fire potential exists. (Ref. 18)

11. Vermiculite filled bags can act as an effective fire protection or flame barrier device. (Oak Ridge tests.) 
X. Ignition Sources and Potential for Fire

A general description of the hazards in the experimental buildings is given below. This description is taken from the document prepared by BNL, "Fire Safety Criteria Exemption Request," January 1971.

"The AGS target building complex is composed of a single fire area with 3 main sections of $25,000,56,000$ and 56,000 sq. ft respectively. The structure is unprotected steel framing with aluminum sandwich panel walls and a metal deck built-up roof. It is single story with a concrete floor at approximately grade level and a height of $52 \mathrm{ft}$ to the lower chord of the truss and $60 \mathrm{ft}$ to the peak of the roof. The building meets the requirements of 'Noncombustible Construction' per NFPA 220. The roofs were designed to BNL fire and safety specifications, and following the CEA incident, cores were taken from the roofs and tested in the Factory Mutual 1aboratory's calorimeter. The roof on the original 25,000 sq. ft section is Factory Mutual Class 2 and the roofs in the other two sections Factory Mutual Class 1. The walls are constructed of two sheets of corrugated aluminum with noncombustible insulation and noncombustible vapor barrier sandwiched between. The building is protected by an automatic fire alarm and detection system utilizing combination FT/RR detectors on the underside of the roof - all in accordance with BNL Fire and Safety Standard No. 1 and NFPA 72D. This system is connected to a Central station in the BNL Fire House. The building is equipped with a continuous sampling combustible gas system located on the underside of the roof and calibrated to alarm and to automatically start high volume exhaust fans located along the peak of the roof, sized to provide a three minute air change throughout the entire volume of the building. The facility is in substantial agreement with the provisions of TID 23992 'Safety Guidelines for High Energy Accelerator Facilities-1967.'

The occupancy of the building is as an experimental hall in which apparatus such as liquid hydrogen-filled targets, 
Cerenkov counters, spark chamber arrays, beam magnets, etc. are located. A large portion of the area is occupied by equipment supporting these experiments including a number of house-type trailers, power supplies, miscellaneous electronic equipment, etc. The particle beams from the particle accelerator are directed through this building into the various pieces of experimental apparatus. In many cases, the beams are shielded with high density concrete block shields.

The principal fire hazards are the liquid hydrogen used in experiments, flammable liquids occasionally used in experiments, the trailers, and combustible materials used for enclosures around experiments; stairways, platforms, etc.

The most serious credible accident would be that of an explosion resulting from a release of hydrogen within the building. The maximum quantity of liquid hydrogen subject to a single accident is in the 75 liter supply dewars. This, of course, is not a sufficient quantity to produce a combustible mixture throughout the building, but if ignited in the flammable range would be expected to produce damage in a limited area. A CEA-type explosion (with similar structural damage) appears remote... in addition to the hazard being limited to smaller quantities, the liquid hydrogen is used at substantially lower operating pressures in the apparatus located within the building (liquid hydrogen bubble chambers are located in other areas). Fire hazards, as noted above, are present but there seems to be no credible mechanism for spreading a fire starting in any piece of apparatus or equipment throughout the facility. The most serious damage that would be expected therefore, would result in high temperatures affecting the strength of the exposed steel above the fire, possibly collapsing the structure and involving on, two, or possibly three of the $25 \mathrm{ft}$ bays.

The consequences of the credible accidents postulated would be principally 1imited to the dollar damage to the equipment and to the building involved. There is no foreseeable damage 
to the accelerator itself, so that experiments being conducted in other buildings would not be interrupted."

(At the present time, quantities of hydrogen, greater than the 75 liters mentioned in the report, may be present in the buildings.)

In a letter to the Laboratory, July 22, 1971, the AEC agreed that no exemption was needed subject to the following conditions:

1. Automatic sprinkler protection for all cable trays within the building, including wall-mounted trays and those within trenches.

2. Local automatic sprinklers mounted above all trailers and all high hazard experimental equipment within the building.

3. Automatic Halon 1301 systems within all trailers.

4. Removal of significant sources of unprotected combustible materials from the Experimental Buildings.

5. Upgrading of the water curtain between the East Experimental Building and the Addition.

The conditions 2,3 and 4 are all in process. At the time of the original exemption request, no investigation had been made into actual potential for fire in the cables and cable trays. If the conditions 2 through 4 are complied with, the major remaining ignition source is a cable failure or short circuit. With our fast acting circuit breakers on all large circuits, the energy is not available to start a large cable fire with cables having a nonpropagating/self-extinguishing jacket. On control and signal cables, vermiculite will provide continuous protection for any type of ignition source. If a fire is generated by a major hydrogen spill as described in the exemption request quoted above, the cables will add a small amount of additional fuel in the direct vicinity of the fire but, protected as described, will not propagate a fire to previously unaffected areas.

Since the cable trays do not present a fire hazard and if conditions 2, 3 and 4 are fulfilled, there is no longer a requirement for an improved 
water curtain between the East Building and EEBA. The large sources of fuel which could contribute to a major fire will be protected or will be removed from the area.

\section{Proposed Protection Schemes}

Based upon the preceding information, the following protection schemes are proposed.

1. For neoprene-jacketed cables, no protection is required since a propagating fire will not be maintained. This covers all $535.3 \mathrm{MCM}$ cable in secondary ac distribution and de distribution in trays, trenches and on the floor. This also applies to the 1000 MCM neoprene-jacketed cables in wall mounted trays.

2. "Flamemastic". or similar compounds may be used to protect cables in special areas, if necessary.

3. Horizontal trays containing control and signal cables will be protected with vermiculite bags.

4. In some special areas where large amounts of control and/or signal cables are in vertical trays, sprinkler protection will be provided. This situation prevails near the computer complex.

5. The horizontal trays carrying the 1000 MCM cross-linked polyethylene triplex cables do not require overall fire protection due to the difficulty of initiating a propagating fire. At intervals, (perhaps at each column location, a $25 \mathrm{ft}$ spacing), fire stops, consisting of a vermiculite bag, will be placed in each tray. These will be 18 in. - 24 in. in length and a bottom cover will be attached to each tray for a length of about 36 in. to retain the vermiculite. These bags will break up the cable trays, very effectively, into $25 \mathrm{ft}$ zones. Tests are underway to ensure that no cable hot spots develop.

Since the burning drippings from one set of cables will not ignite the set below, no covers are required on the trays. A "drip pan" will be installed beneath the bottom tray to prevent burning drippings from igniting combustible materials at the floor level underneath the trays. 
6. The following conditions referred to, in the exemption request report, will be complied with:

a. Halon 1301 protection inside trailers

b. Sprinkler protection on outside of trailers

c. Local sprinkler protection of hazardous experimental equipment.

MP :peh

Distr.: AD S\&P, AEC

CERN 
XII. Bibliography

The following references were used in the preparation of this report:

1. Charles E. McCormack, E.I. duPont DeNemours \& Co., Inc., "Neoprene and Hypalon-Flame Resistance and Thermal Decomposition," Paper presented at The Connecticut Rubber Group, November 11, 1971.

2. U.S. Dept. of Interior, Bureau of Mines Schedule 2G, "Electric Motor-Driven Mine Equipment and Accessories," March 19, 1968.

3. Cerro Wire and Cable Company - Rockbestos Division, "Rockbestos Wire and Cable Handbook for Flame Retardant and Radiation Resistant Cables."

4. Anaconda Copper - Specifications for Electrical Conductors - Rubber Cables - GP-CS-432-0, November 1969, and Thermoset P1astic Cables GP-CS-320-5, September 1971.

5. Florida Power and Light Company - System Test Lab, October 18, 1967, Test No. 21-M-7, January 1970, "Sprayable Fireproofing."

6. Factory Mutual Research Corp., Test of Flamemastic 71A, July 22, 1970.

7. Dyna-Therm Corp. Catalog on Flamemastic (contains copies of reports of six independent tests on Flamemastic).

8. GE Seminar Report, "Flame Testing of Control Cables," New York, New York, July 7, 1971.

9. GE Wire and Cable Engineering - Materials Analysis and Testing Laboratory, Test Method Number MAT-030-A-Tray Cable Flame Test, February 2, 1971.

10. J.W. Robertson, "New Flame Tests for Control and Power Cable," Paper presented to Electrical Insulation and Wire Technology Conf. New York, June $29-30,1971$.

11. P. Bhatia and $\mathrm{W}$. Wade Brown, Baltimore Gas and Electric Co., "Flame Propagation Tests on 600 Volt Control and Power Cables in Trays for Calvert Cliffs Nuclear Power Plant," IEEE Summer Meeting, Portland, Oregon, July 18-23, 1971. 
12. I.E. Oldendorf, AEC, "Evaluation of Today's Grouped Electrical Cable Fire Problem," 75th NFPA Annual Meeting, San Francisco, California, May 21, 1971.

13. Underwriters' Laboratories, Inc., "Proposal for the Investigation of the Flame Retardant Properties of Power and Control Cables Intended for Installation in Trays," (undated).

14. J. Forencsik, Philadelphia Electric Co., "Peach Bottom Fire Spurs Improved Cable Design," Electrical World, November 15, 1971.

15. F. E. Baker, R.E. Shepherd, Goodyear Atomic Corp., "Fire Testing of Electrical Cables and the Benefits of Fire Retardant Paints," Fire Technology, November 1971.

16. F.R. Postma and F.M. McAvoy, Okonite Co. "Discussion for the Working Group on Wire and Cable Systems of the Station Design Subcommittee of the IEEE Power and Generation Committee," July 1971.

17. E.E. McIlveen, and F.R. Postma, Okonite Co. Electrical Systems and Equipment Committee of E.E.I., Miami, Florida, February 15, 1971.

18. F.M. McAvoy, Okonite Co. "Flame Tests - A System Approach for Power and Control Cable," IEEE Winter Meeting, New York, January 31, 1972 .

19. IPCEA Handbook.

20. Specification for AGS Conversion Multiconductor Control Cable, Revision B, AGSCD Spec. 587, January 15, 19.71. 


\section{Figure Captions}

Fig. 1 AGS Area Layout.

Fig. 2 Triplex Cable Arrangement in Tray.

Fig. 3 Setup for Oxygen-Index Test

Fig. 4 Oxygen-Index Ranges for Various Materials.

Fig. 5 Test E-4 Setup Vertica1 - Two Neoprene - One Cross-Iinked Polyethylene Cable.

Fig. 6 Test E-4 - Two Minutes.

Fig. 7 Test E-4 - Five Minutes.

Fig. 8 Test E-4 - Ten Minutes.

Fig. 9 Test E-4 - Twenty Minutes.

Fig. 10 Test E-4 - Flame Removed After Twenty Minutes.

Fig. 11 Test E-5 - Horizontal Triplex - Cross-Linked Polyethylene Cables - Test Setup.

Fig. 12 Test E-5 - Two Minutes.

Fig. 13 Test E-5 - Five Minutes.

Fig. 14 Test E-5 - Ten Minutes.

Fig. 15 Test E-5 - Fifteen Minutes.

Fig. 16 Test E-5 - Twenty Minutes.

Fig. 17 Test E-5 - Flame Removed at Twenty Minutes.

Fig. 18 Test E-5 - Cables Turned Over to Show Damage on Bottom Side.

Fig. 19 Test E-7 - Vertical Test - Three Cross-Linked Polyethylene Cables.

Fig. 20 Test E-7 - Two Minutes.

Fig. 21 Test E-7 - Five Minutes.

Fig. 22 Test E-7 - Ten Minutes.

Fig. 23 Test E-7 - Fifteen Minutes. 
Fig. 24 Test E-7 - Twenty Minutes.

Fig. 25 Test E-7 - Twenty-five Minutes.

Fig. 26 Test E-7 - Thirty Minutes.

Fig. 27 Test E-7 - Thirty-five Minutes,

Fig. 28 Test E-7 - Flame Removed at Thirty-five Minutes. 


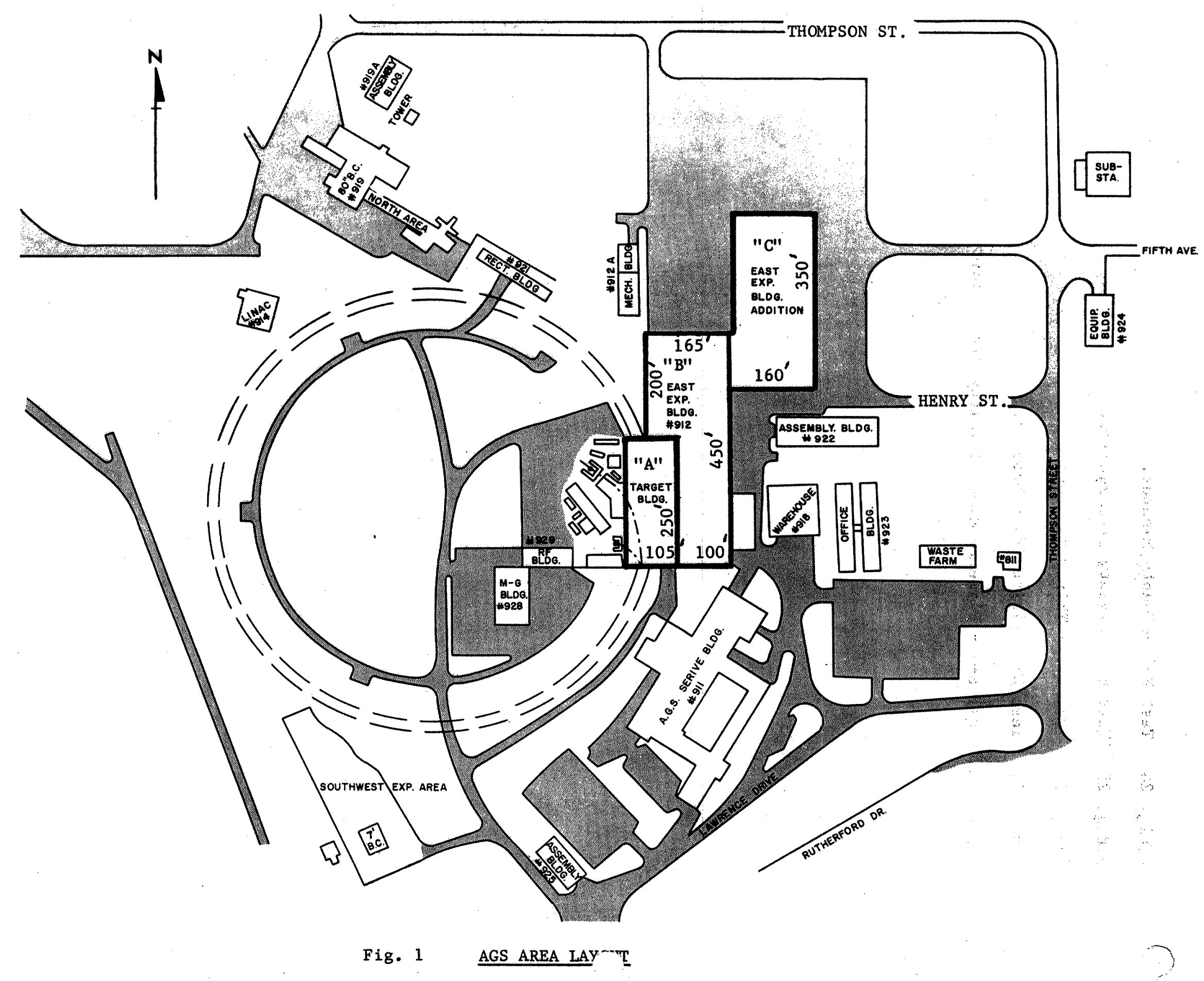




\section{OXYGEN INDEX OF INSULATION AND JACKET COMPOUNDS}

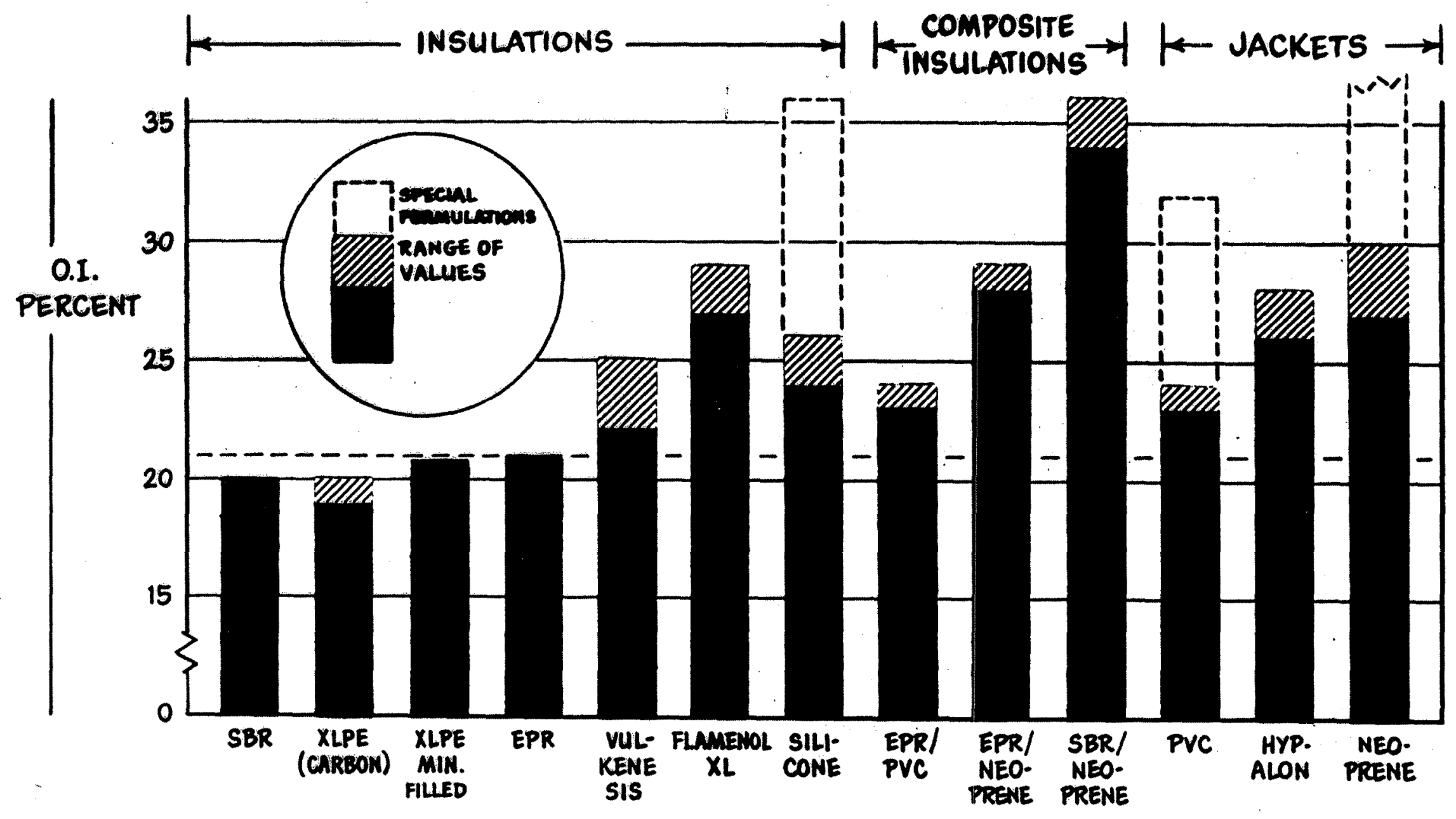

Fig. 2. Triplex Cable Arrangement in Tray 
$C$

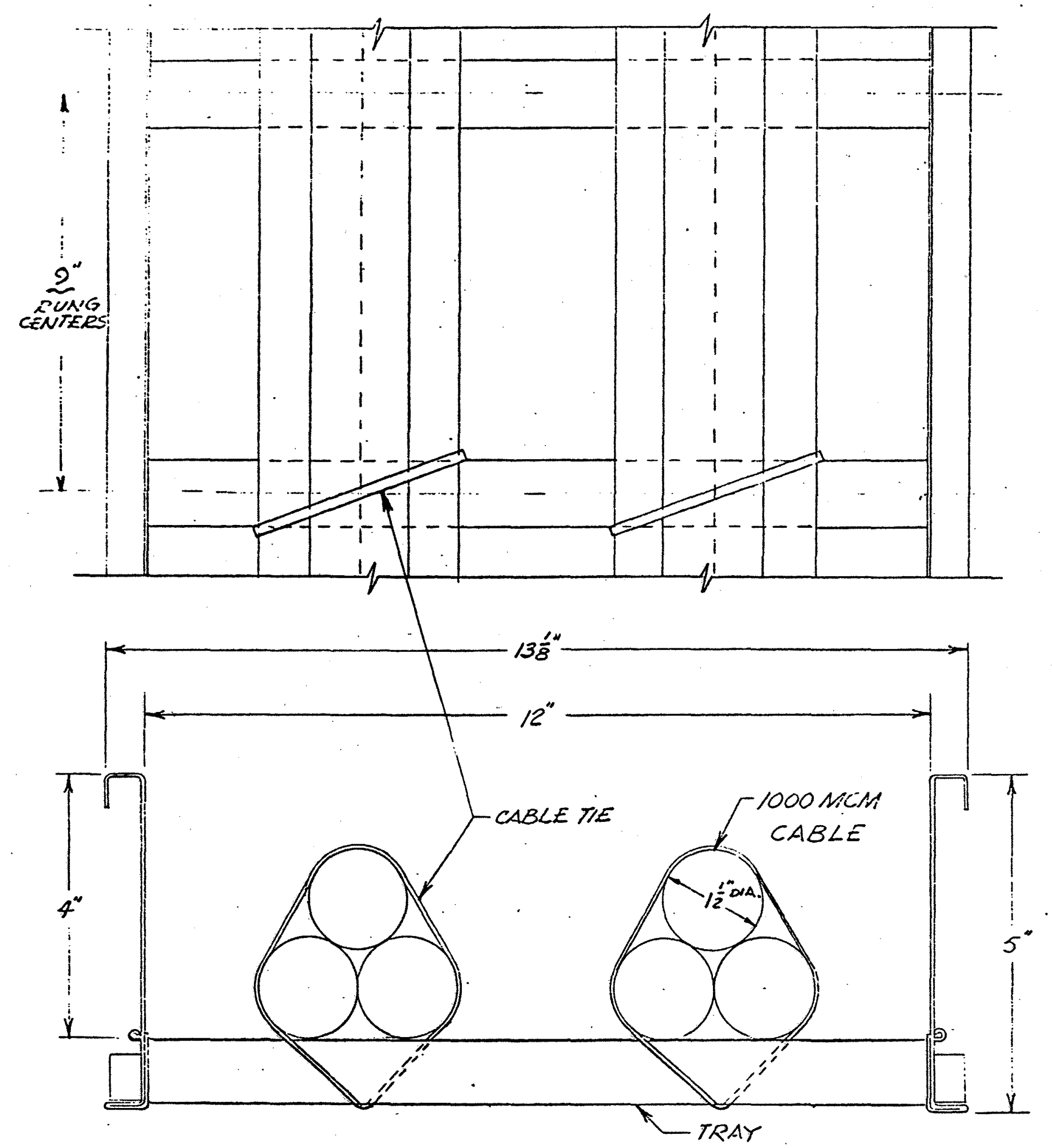

Fig. 3. Setup for Oxygen-Index Test 


\section{OXYGEN INDEX TEST}

\section{ASTM D 2863-70}

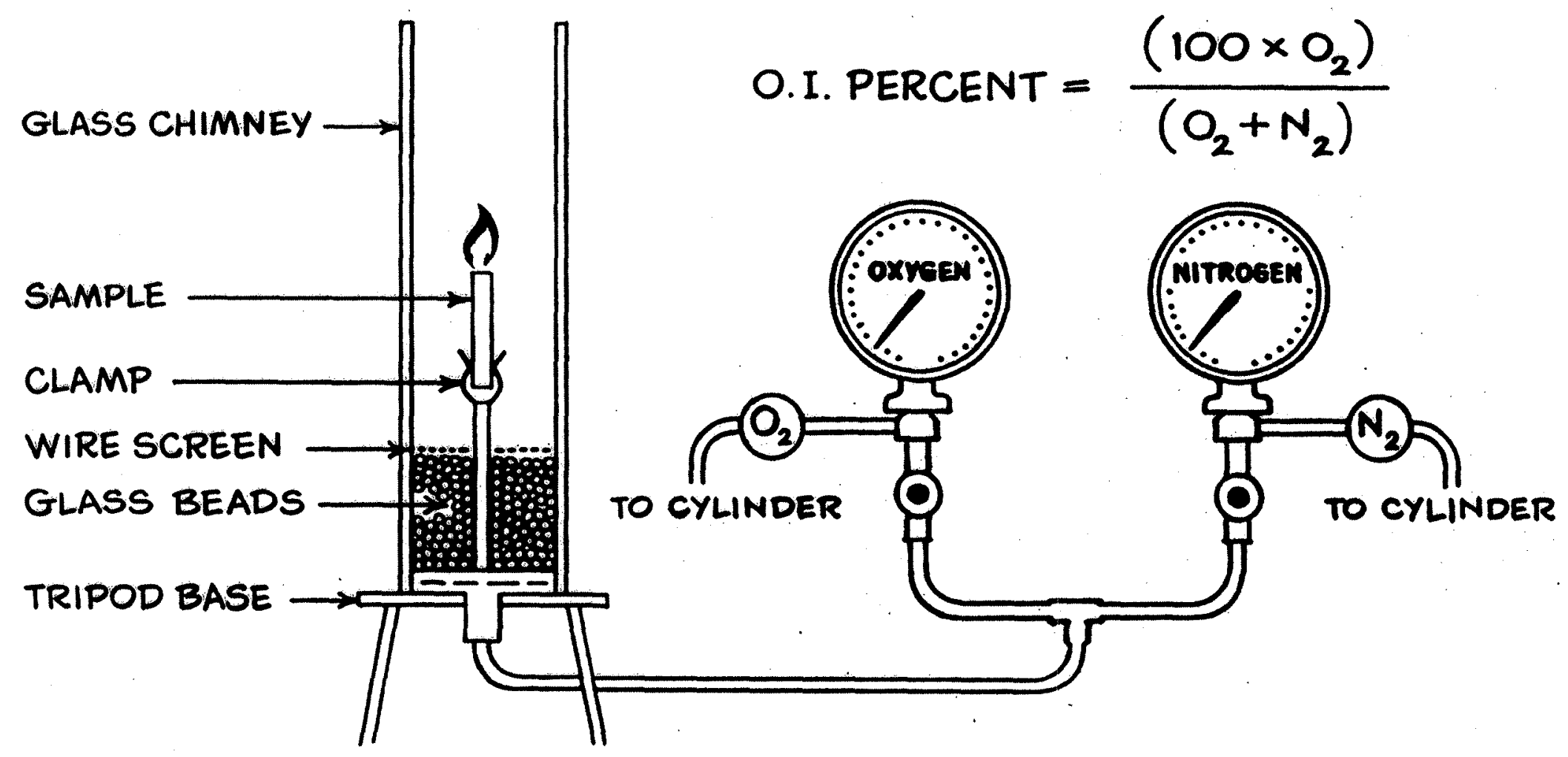

Fig. 4. Oxygen-Index Ranges for Various Materials 

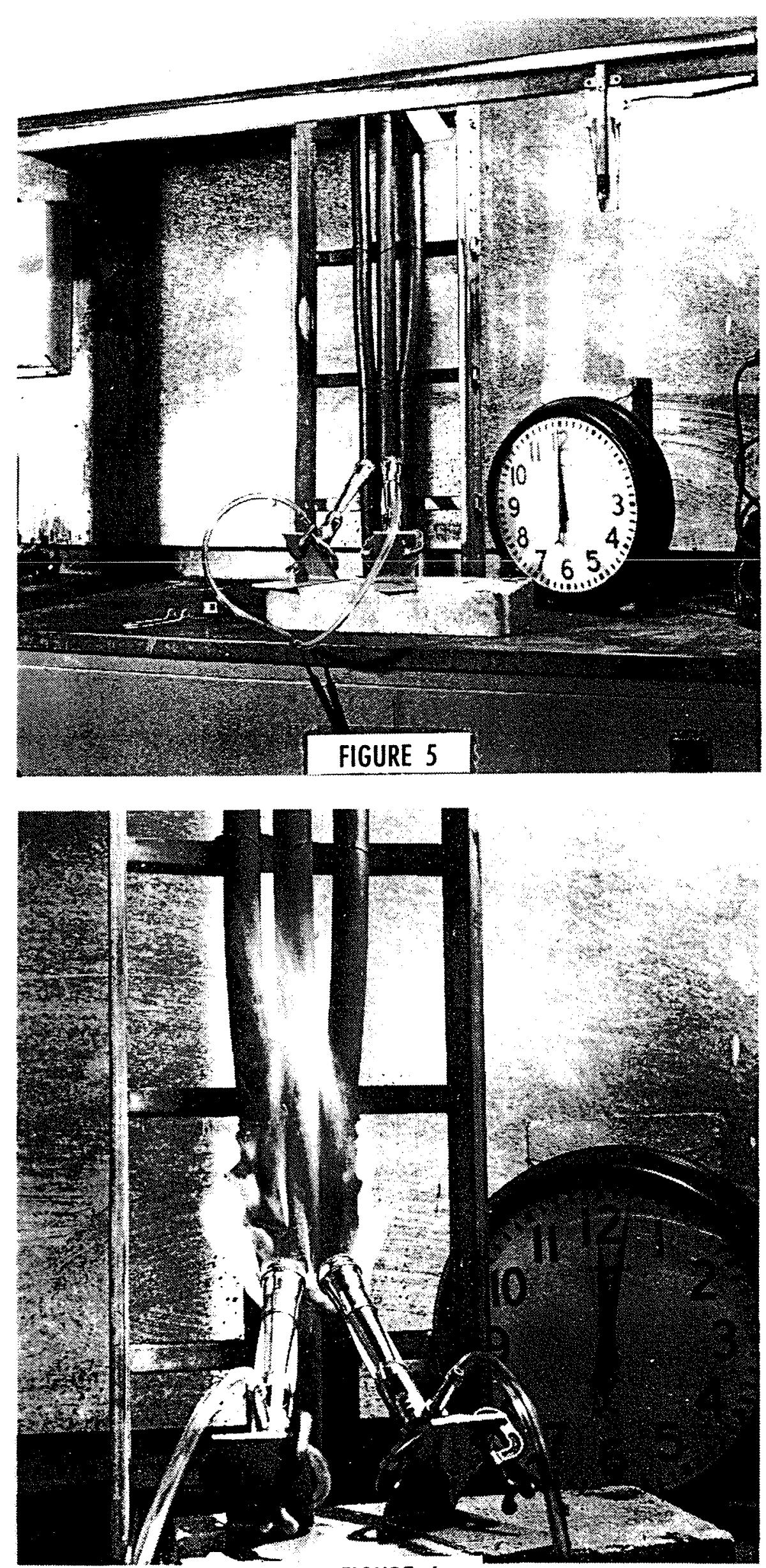

FIGURE 6 

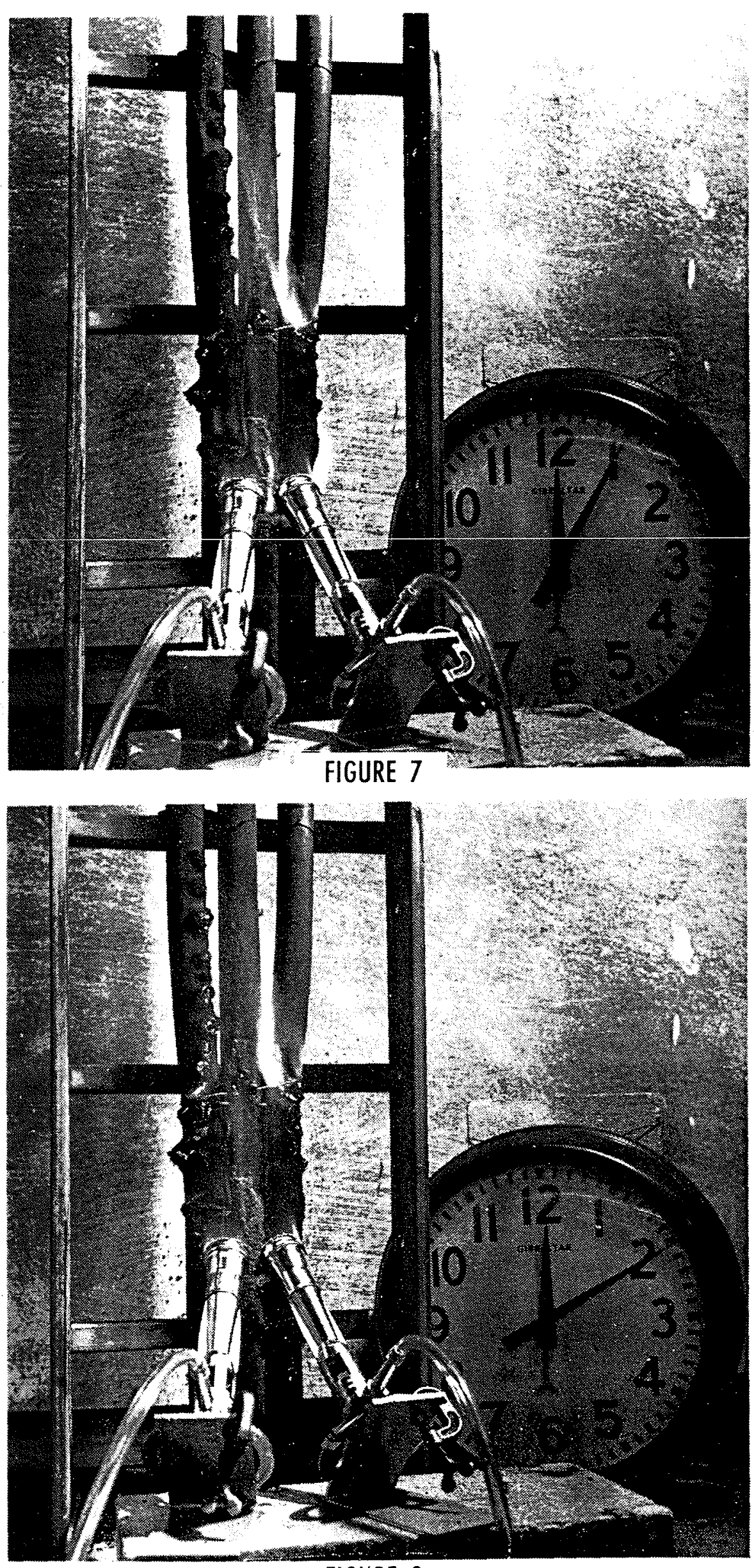

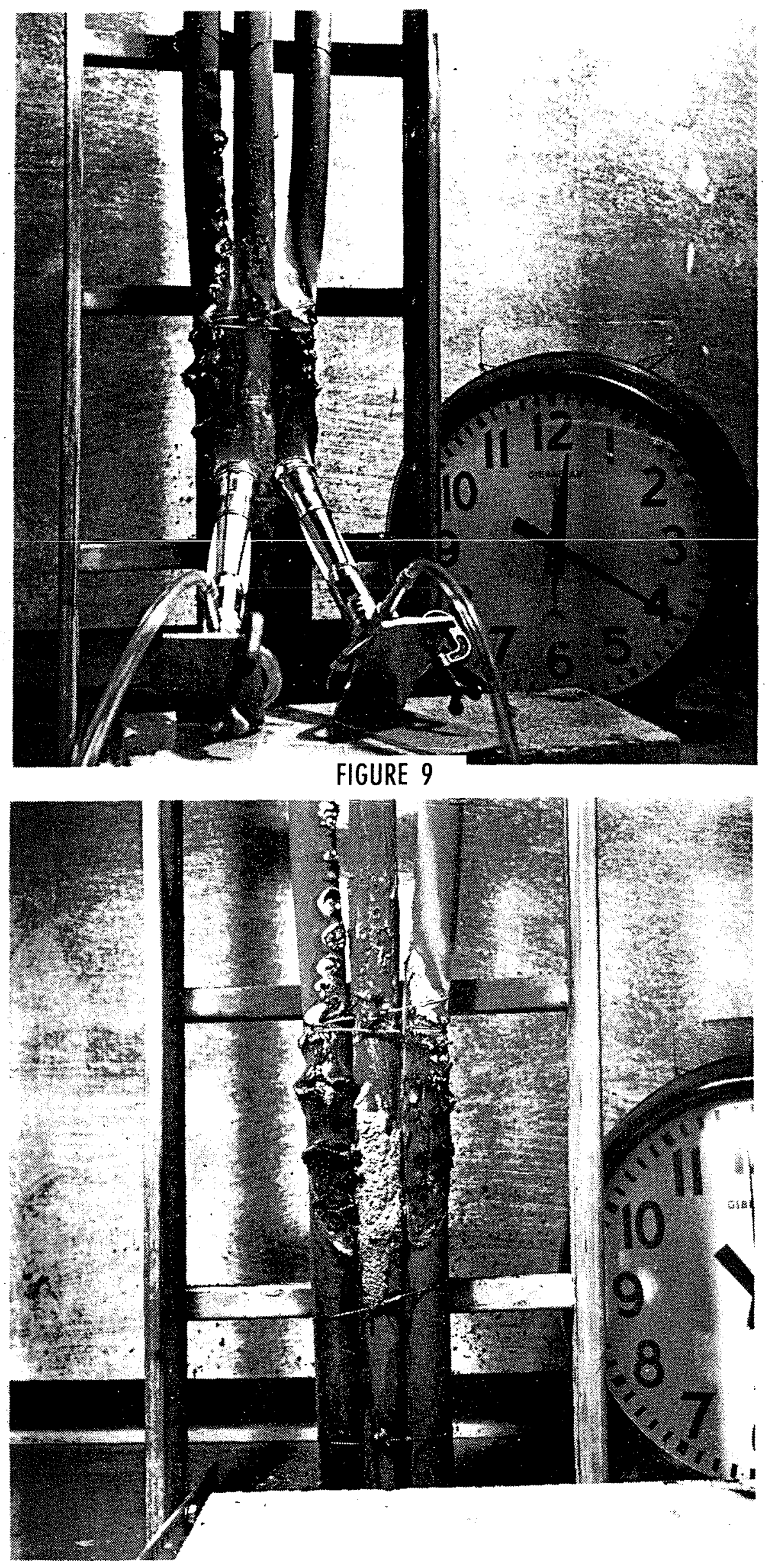

FIGURE 10 

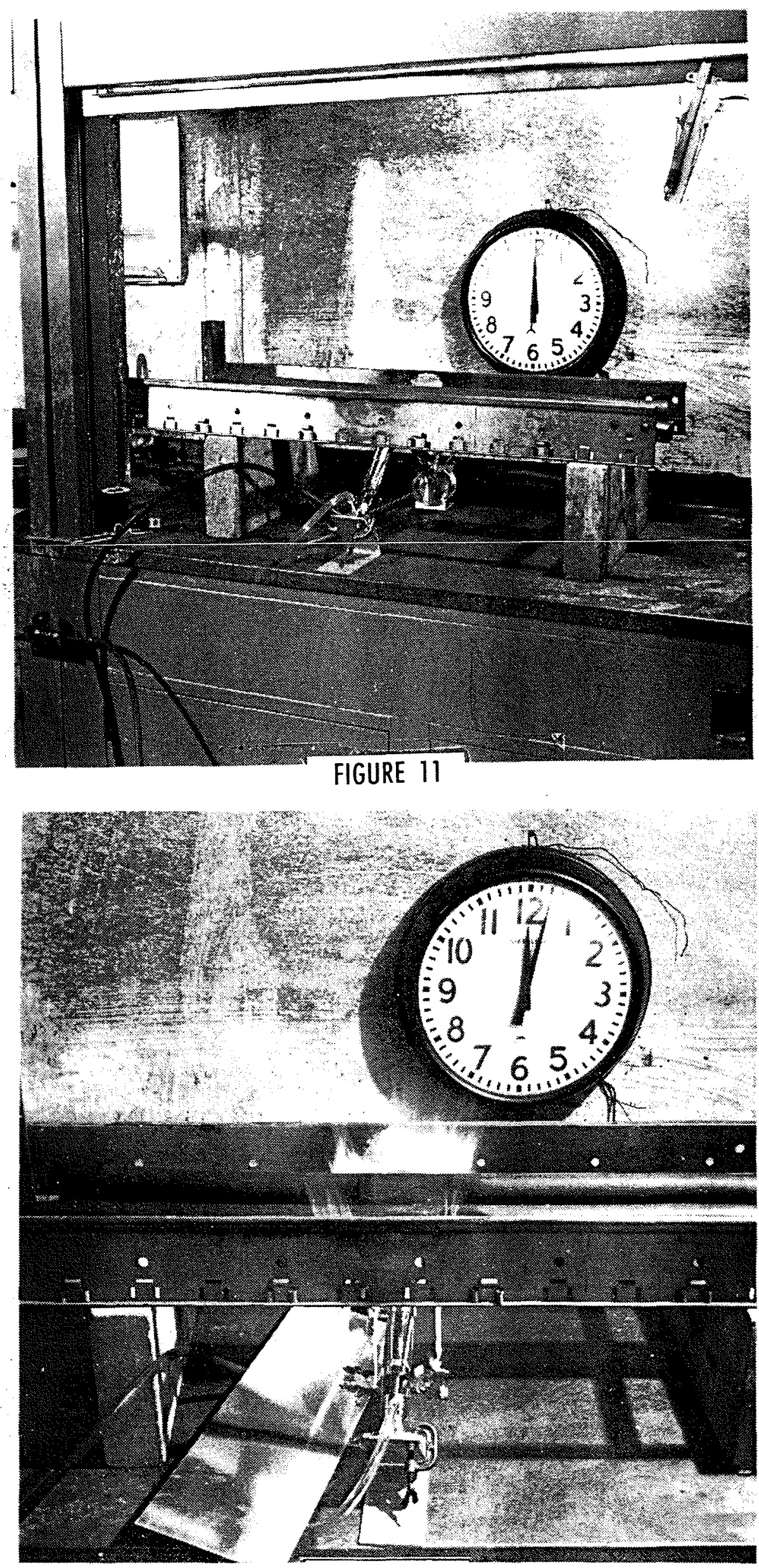

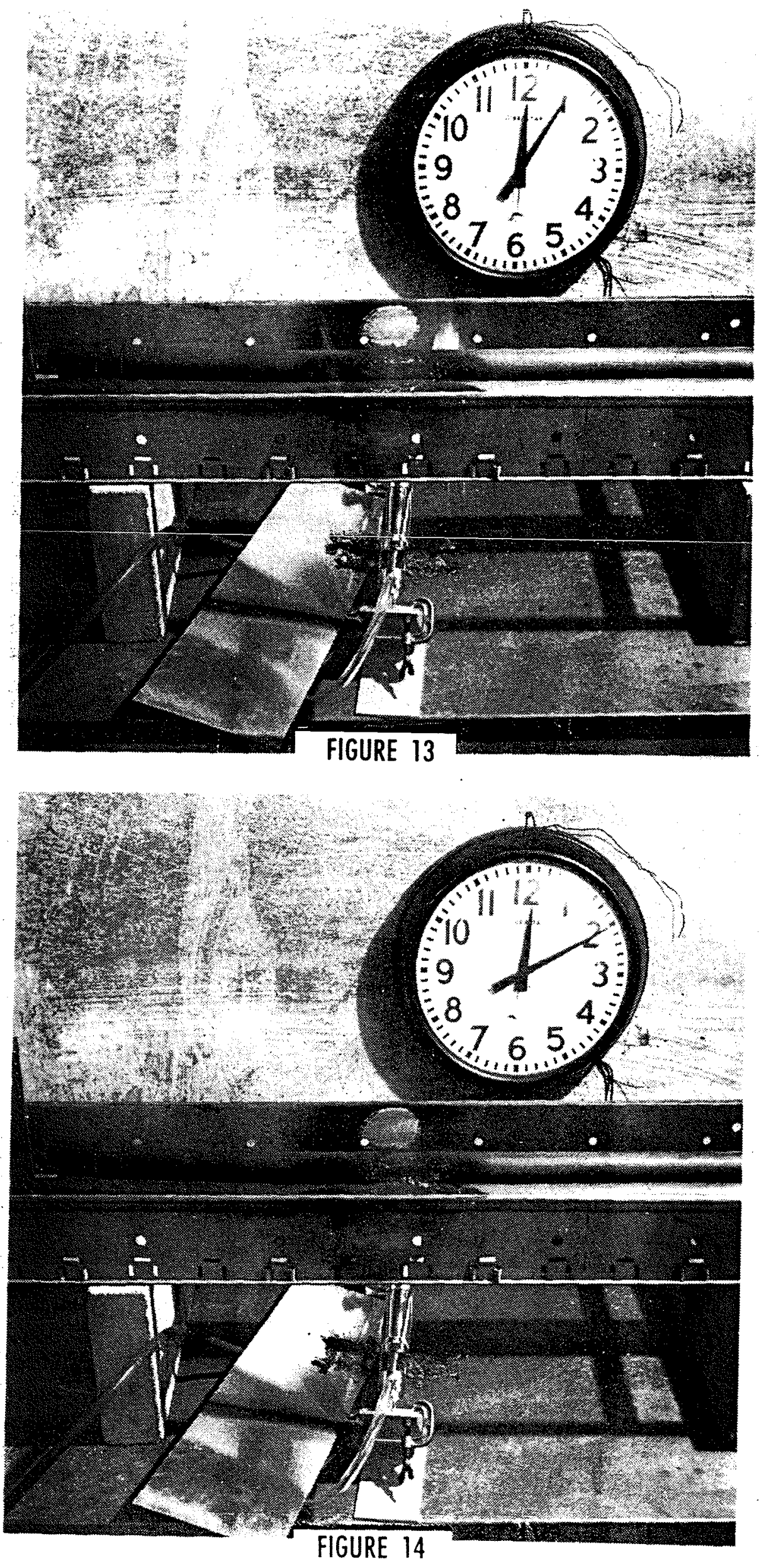

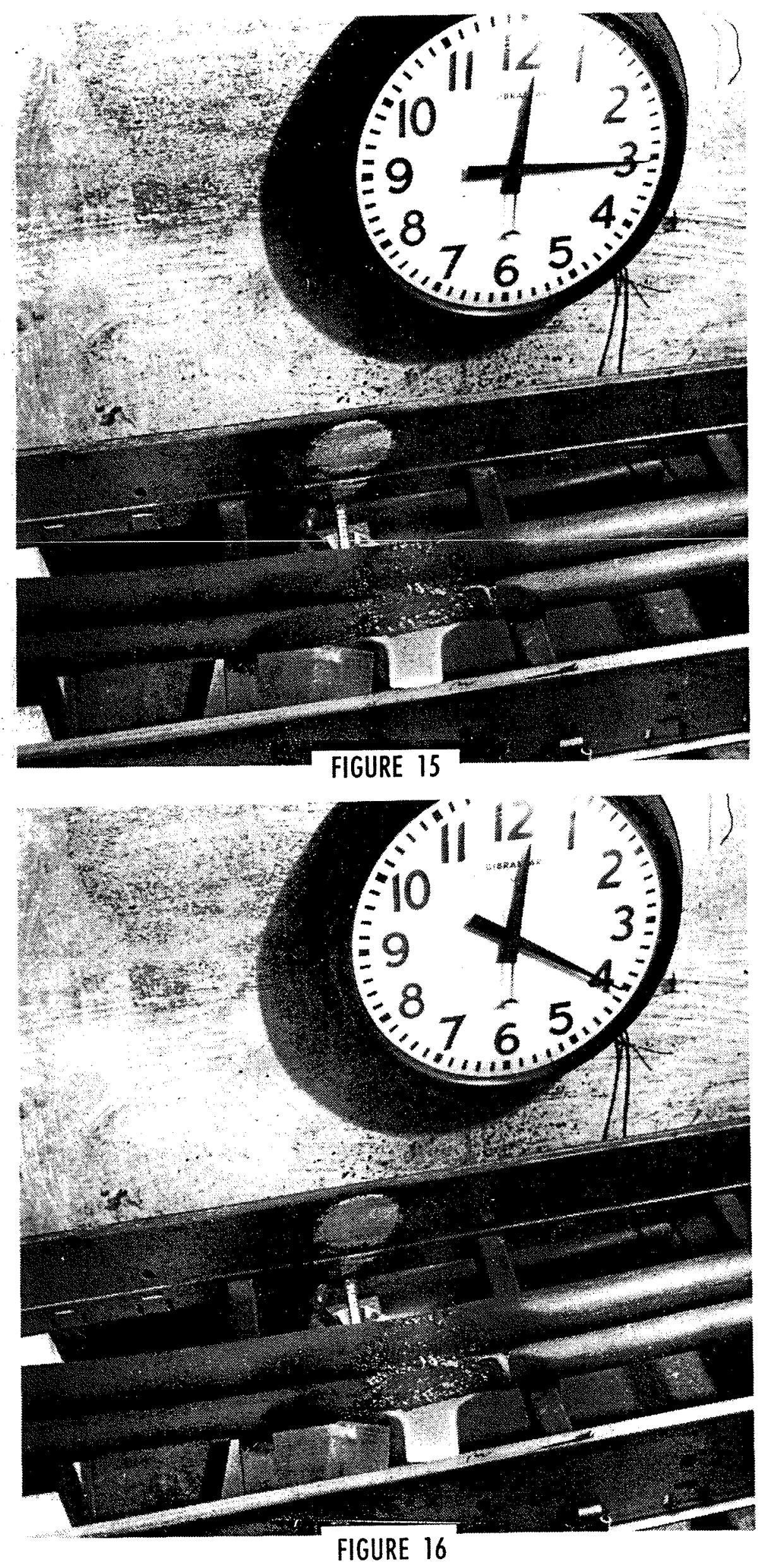

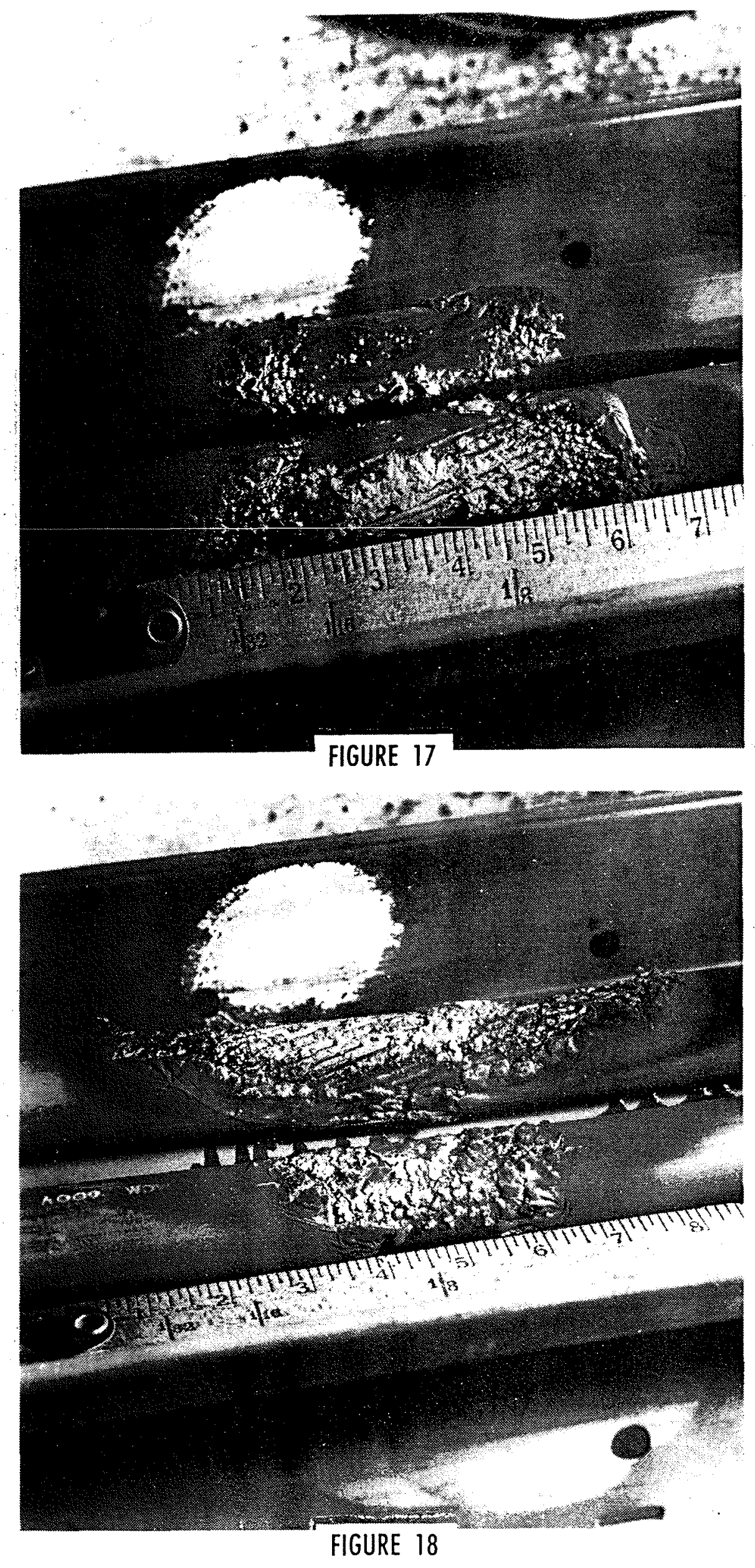



FIGURE 20 

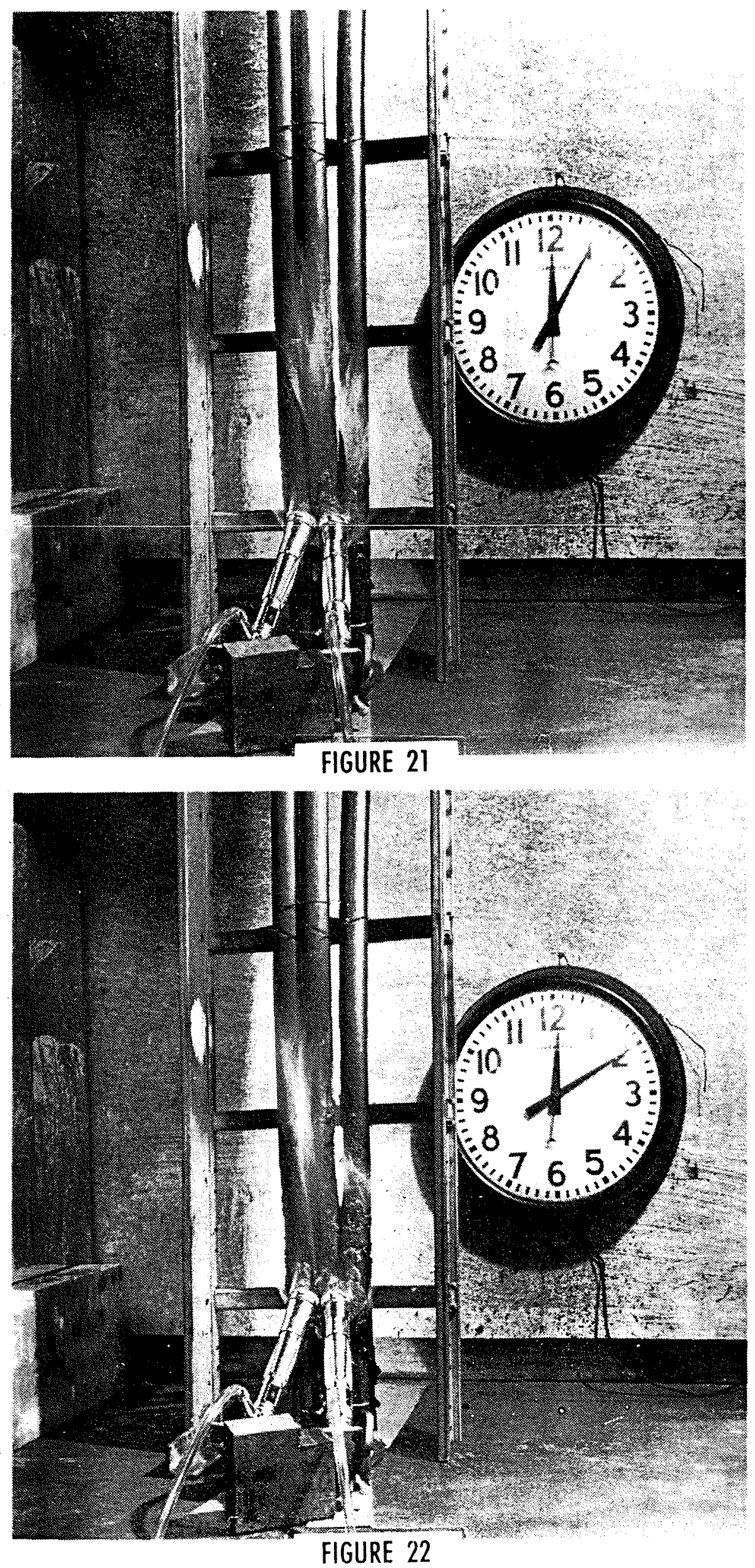

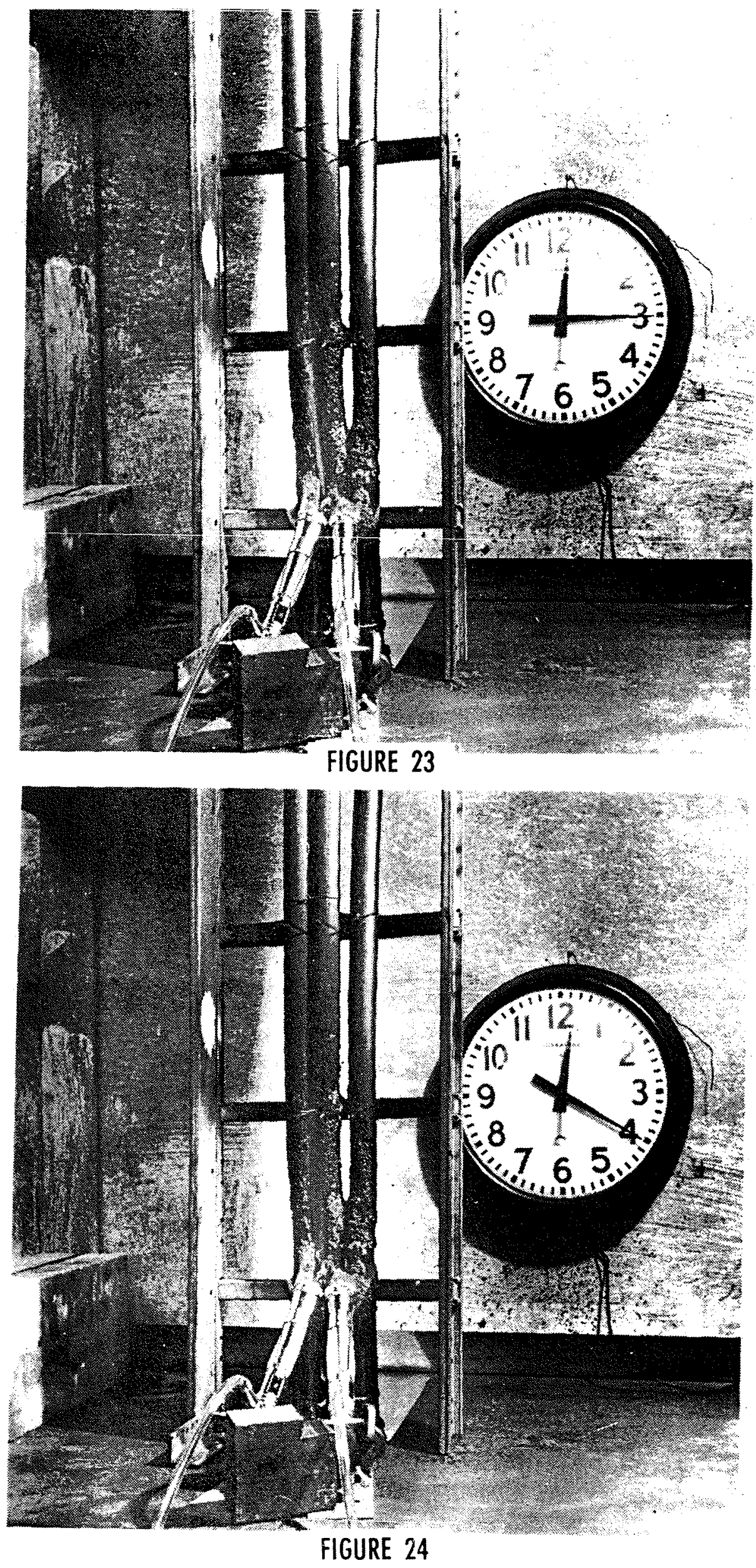

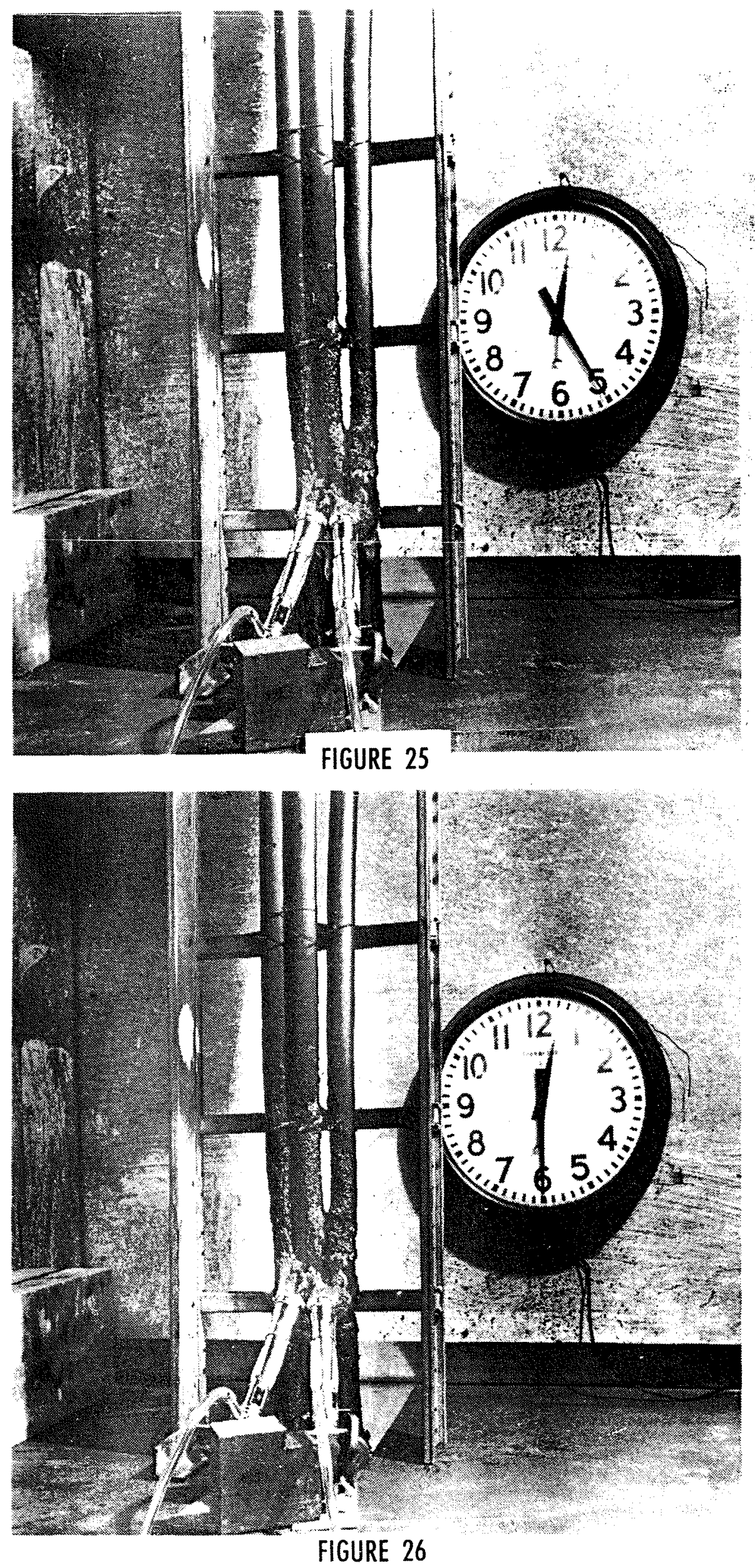


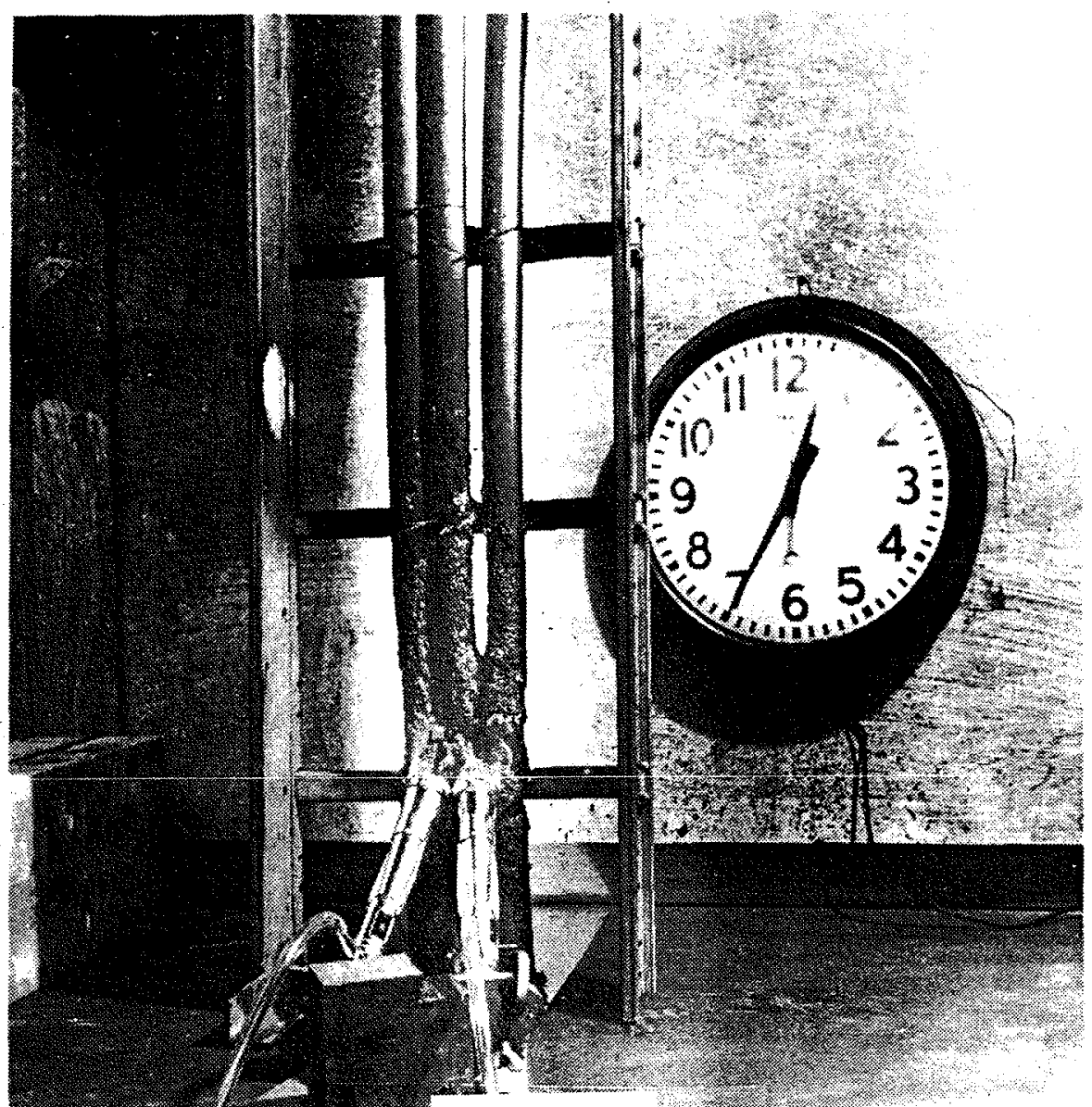

FIGURE 27

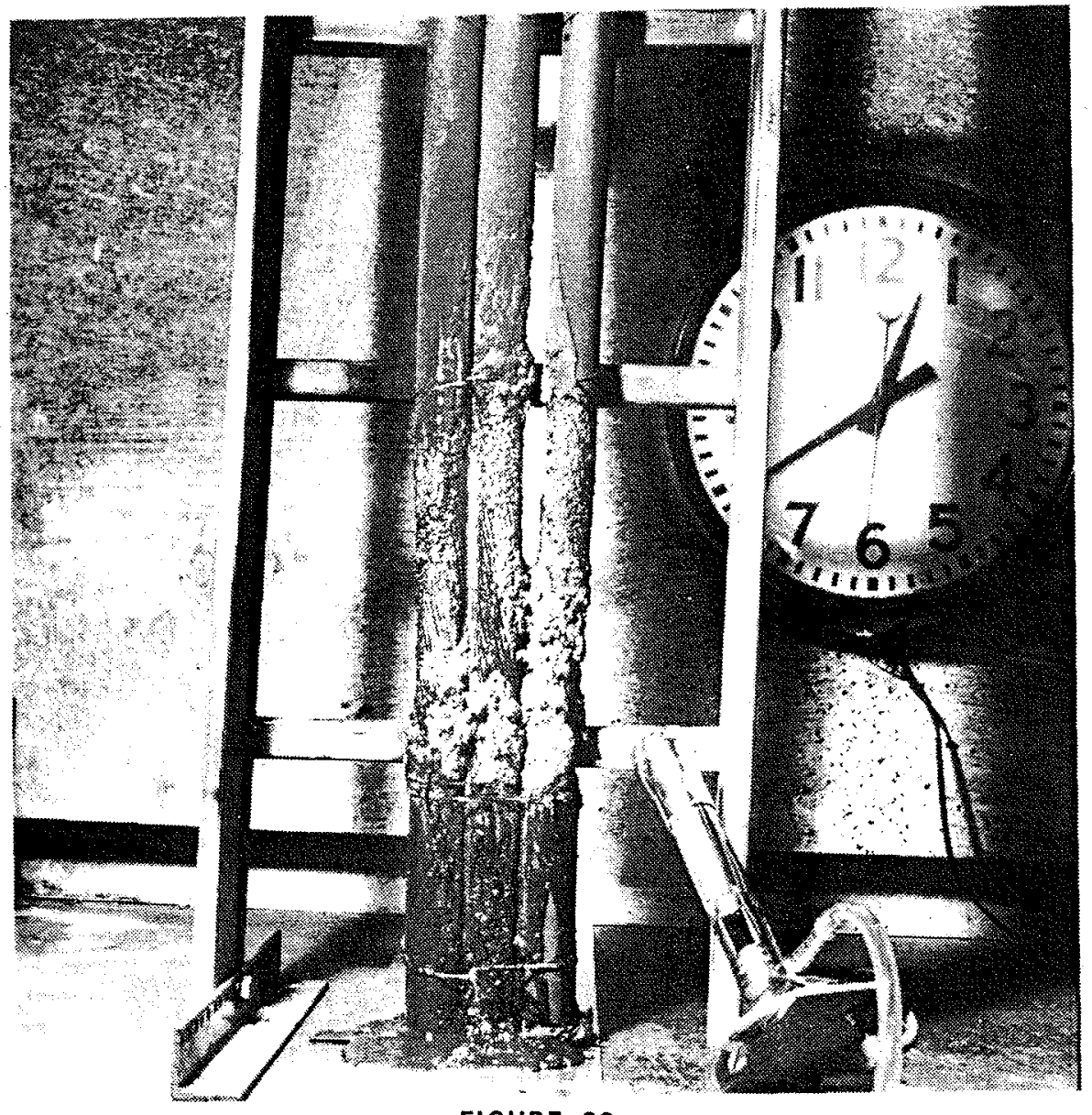

FIGURE 28 
